\title{
Divalent nutrient cations: friend and foe during zinc stress in rice
}

\author{
Boon Huat Cheah ${ }^{1}$, Yu-Ling Chen ${ }^{1}$, Jing-Chi Lo ${ }^{2}$, I-Chien Tang ${ }^{2}$, Kuo-Chen Yeh ${ }^{2}$, and \\ YA-FEN LIN ${ }^{1}$ \\ ${ }^{1}$ National Taiwan University \\ ${ }^{2}$ Academia Sinica
}

July 16, 2020

\begin{abstract}
Zn deficiency is the most common micronutrient deficit in rice but also a widespread industrial pollutant. It is unclear how rice responds to $\mathrm{Zn}$ depletion or excess, and which signaling molecules link the affected physiological processes. We therefore compared the physiological, transcriptomic and biochemical properties of rice plants subjected to Zn starvation or excess at early and later treatment stages. Both forms of $\mathrm{Zn}$ stress inhibited root and shoot growth. Several divalent cations $(\mathrm{Fe}, \mathrm{Cu}, \mathrm{Ca}, \mathrm{Mn}$ and $\mathrm{Mg}$ ) accumulated in $\mathrm{Zn}$-depleted shoots, possibly due to the increased synthesis and activity of promiscuous Zn transporters and chelators. Gene Ontology enrichment analysis of 970 differentially expressed genes revealed overrepresentation of ion and oligopeptide transport, antioxidative defense and secondary metabolism. The expression of genes encoding Fe/Ca-binding peroxidases was activated after 3 days of $\mathrm{Zn}$ starvation, boosting the activity of ascorbate peroxidase and thus scavenging $\mathrm{H}_{2} \mathrm{O}_{2}$ more effectively to prevent leaf chlorosis. Conversely, excess $\mathrm{Zn}$ triggered the expression of genes encoding Mg-binding proteins (OsCPS2/4 and OsKSL4/7) required for antimicrobial diterpenoid biosynthesis. We demonstrated the key components of crosstalk between $\mathrm{Zn}$ and other divalent cations under $\mathrm{Zn}$ stress conditions, leading to the regulation of gene expression and corresponding biochemical and physiological processes.
\end{abstract}

Running head: Zn stress induced physiological responses

Divalent nutrient cations: friend and foe during zinc stress in rice

Boon Huat Cheah ${ }^{1+}$, Yu-Ling Chen ${ }^{1+}$, Jing-Chi Lo ${ }^{2}$, I-Chien Tang ${ }^{2}$, Kuo-Chen Yeh $^{2}$, Ya-Fen Lin ${ }^{1 *}$

${ }^{1}$ Department of Agronomy, National Taiwan University, Taipei 10617, Taiwan

${ }^{2}$ Agricultural Biotechnology Research Center, Academia Sinica, Taipei 11529, Taiwan

+ These authors contributed equally to this work.

\section{* Correspondence}

Ya-Fen Lin, Department of Agronomy, National Taiwan University, Taipei 10617, Taiwan

Email: yafenlin0725@ntu.edu.tw

Funding information

This work was supported by a grant from the Ministry of Science and Technology, Taiwan, grant number 107-2313-B-002-011-MY2.

Abstract

Zn deficiency is the most common micronutrient deficit in rice but also a widespread industrial pollutant. It is unclear how rice responds to $\mathrm{Zn}$ depletion or excess, and which signaling molecules link the affected 
physiological processes. We therefore compared the physiological, transcriptomic and biochemical properties of rice plants subjected to Zn starvation or excess at early and later treatment stages. Both forms of Zn stress inhibited root and shoot growth. Several divalent cations ( $\mathrm{Fe}, \mathrm{Cu}, \mathrm{Ca}, \mathrm{Mn}$ and $\mathrm{Mg}$ ) accumulated in Zn-depleted shoots, possibly due to the increased synthesis and activity of promiscuous Zn transporters and chelators. Gene Ontology enrichment analysis of 970 differentially expressed genes revealed overrepresentation of ion and oligopeptide transport, antioxidative defense and secondary metabolism. The expression of genes encoding $\mathrm{Fe} / \mathrm{Ca}$-binding peroxidases was activated after 3 days of $\mathrm{Zn}$ starvation, boosting the activity of ascorbate peroxidase and thus scavenging $\mathrm{H}_{2} \mathrm{O}_{2}$ more effectively to prevent leaf chlorosis. Conversely, excess $\mathrm{Zn}$ triggered the expression of genes encoding Mg-binding proteins (OsCPS2/4and OsKSL4/7) required for antimicrobial diterpenoid biosynthesis. We demonstrated the key components of crosstalk between $\mathrm{Zn}$ and other divalent cations under Zn stress conditions, leading to the regulation of gene expression and corresponding biochemical and physiological processes.

Keywords: zinc deficiency, excess zinc, Oryza sativa L., nutrient homeostasis, iron, calcium, magnesium, reactive oxygen species, diterpenoids

\section{Introduction}

Zinc $(\mathrm{Zn})$ is one of the eight essential micronutrients in plants required for normal development and defense (Marschner, 2011; Cabotet al ., 2019). Zn-binding proteins account for more than $10 \%$ of the eukaryotic proteome (Andreini, Banci, Bertini \& Rosato, 2006) and include 300 Zn-binding enzymes belonging to all six major enzyme classes (Sagardoy, Morales, López-Millán, Abadía \& Abadía, 2009). Zn acts as a structural, regulatory or catalytic cofactor for these proteins (McCall, Huang \& Fierke, 2000; Saravanan, Vasu, Ghosh \& Nagaraja, 2007). Well-known Zn-binding proteins include Zn-finger domain transcription factors, superoxide dismutase (SOD), carbonic anhydrase and RNA polymerase (Eide, 2011). They regulate a wide range of physiological processes, including gene expression, photosynthesis, protein synthesis, hormone production, and stress responses, and they also play key roles in carbohydrate, lipid and nucleic acid metabolism (Stoyanova \& Doncheva, 2002; López-Millán, Ellis \& Grusak, 2005; Hafeez, Khanif \& Saleem, 2013; Cabot et al ., 2019). Zn deficiency and excess both trigger adverse effects on plant physiology and metabolism, so Zn levels must be tightly regulated and maintained within an optimal range (Clemens, 2001; Palmgren et al ., 2008; Ishimaru, Bashir \& Nishizawa, 2011; Lin \& Aarts, 2012).

Zn homeostasis in plants is controlled in part by F-group bZIP (basic leucine zipper) transcription factors that regulate ZIPtransporter genes (zinc-regulated transporters, iron-regulated transporter-like protein). In Arabidopsis (Arabidopsis thaliana), two F-group bZIP proteins (AtbZIP19 and AtbZIP23) bind the zinc deficiency response element (ZDRE) located in the promoter region of a small group of Zn homeostatic genes encoding ZIP transporters (AtZIP1 /3/4/5/9/10 /12 andAtIRT3 ) and nicotianamine synthases (AtNAS2 14 ) (Assunção et al ., 2010; Assunção et al ., 2013). Overexpressing either AtbZIP19 or AtbZIP23 in the Arabidopsis bzip19bzip23 double mutant rescues the mutant's hypersensitivity to Zn deficiency (Assunção et al ., 2010; Lilay, Castro, Campilho \& Assunção, 2019). Recently, AtbZIP19 and AtbZIP23 have been shown to act as $\mathrm{Zn}$ sensors because they contain a $\mathrm{Zn}$ sensor motif that can bind to $\mathrm{Zn}^{2+}$ ions, and mutation of this motif affects Zn binding and eventually leads to a constitutive transcriptional Zn deficiency response (Lilay et al ., 2020b). The rice (Oryza sativa) genome contains 16 paralogous OsZIPgenes (Tiong et al ., 2015). Complementation assays in yeast have shown that OsZIP1/3/4/5/7/8/9 are functional Zn transporters (Ramesh, Shin, Eide \& Schachtman, 2003; Ishimaru et al ., 2005; Yang, Huang, Jiang \& Zhang, 2009; Lee et al ., 2010a; Lee, Kim, Lee, Guerinot \& An, 2010b; Tan et al ., 2019; Huang et al ., 2020). OsZIP1/9 facilitate Zn uptake in roots whereas OsZIP4/5/7/8 control Zn translocation or distribution in shoots (Huang et al ., 2020). The F-bZIP-mediated Zn deficiency response in Arabidopsis is conserved in barley (Hordeum vulgare ), wheat (Triticum aestivum ) and rice (Castro et al ., 2017; Evens, Buchner, Williams \& Hawkesford, 2017; Nazri, Griffin, Peaston, Alexander-Webber \& Williams, 2017; Lilay et al ., 2020a). OsbZIP48 and OsbZIP50 are the rice F-bZIP homologs that regulate the Zn deficiency response (Lilay et al ., 2020a). 
If Zn homeostasis fails, many physiological and metabolic processes are affected. Rice plants starved of Zn therefore display symptoms such as bronzed leaves, short internodes, fewer tillers, delayed development, and low grain yields (Yoshida \& Tanaka, 1969; Widodo et al ., 2010). On the other hand, Zn toxicity symptoms include leaf chlorosis and the inhibition of growth and flowering (Silva, Vitti \& Trevizam, 2014). The production of gibberellin (GA) and indole-3-acetic acid (IAA) is repressed by Zn starvation in tomato (Solanum lycopersicum ) and maize (Zea mays ) plants (Takaki \& Kushizaki, 1977; Sekimoto, Hoshi, Nomura \& Yokota, 1997), whereas the application of exogenous GA alleviates growth attenuation in rice seedlings exposed to excess Zn (Nag, Nag, Paul \& Mukherji, 1984). Zn starvation and excess both disrupt the balanced production and removal of reactive oxygen species (ROS), leading to the accumulation of ROS and oxidative damage to major cellular structures (Apel \& Hirt, 2004; Holler, Hajirezaei, Von Wirén \& Frei, 2014; Feigl et al ., 2015). For example, Zn deficiency increases membrane permeability mainly by the peroxidation of unsaturated fatty acids (Cakmak, 2000). Exposure to photo-oxidative stress (light-dependent generation of ROS) therefore disrupts chlorophyll synthesis, photosynthetic electron transport and carbohydrate metabolism in chloroplasts (Bae, Oh, Rhee \& Yoo, 2011).

Transcriptomic studies have shown that $\mathrm{Zn}$ starvation modulates the expression of genes encoding transporters, enzymes involved in the synthesis of phytosiderophores, organic acids and phytohormones (Suzukiet al ., 2012; Bandyopadhyay, Mehra, Hairat \& Giri, 2017; Zeng, Zhang, Ding, Zhang \& Zhu, 2019a). Previous studies in rice have mainly compared responses to Zn deficiency in different cultivars and varieties. For example, the transcriptomic profiles of roots (particularly crown roots) and shoots were compared in lines RIL46, IR55179 and Nipponbare (which tolerate Zn deficiency) and lines IR26, IR74 and IR64 (which do not) under normal conditions and Zn deprivation (Widodo et al ., 2010; Nanda, Pujol \& Wissuwa, 2017; Zeng, Zhang, Ding \& Zhu, 2019b). The unique gene expression profile of line RIL46 explained its ability to outperform line RIL74 in terms of root growth, the efflux of phytosiderophores and organic acids, and the uptake of Zn-chelator complexes in response to Zn starvation (Widodo et al ., 2010). The more efficient relocation of $\mathrm{Zn}$ to roots allowing the better maintenance of crown root growth in Zn-efficient rice genotypes was explained by the unique expression of various Zn-finger, hormone-responsive and transporter genes (Nanda et al ., 2017). Conversely, transcriptomic studies of rice seedlings exposed to excess Zn are rare. A comprehensive comparison of the rice transcriptome under normal conditions, $\mathrm{Zn}$ starvation and excess $\mathrm{Zn}$ is therefore needed to better understand how rice plants address $\mathrm{Zn}$ stress.

The regulation of Zn deficiency and homeostasis in Arabidopsis is closely linked to the regulation of other micronutrients (Lilay et al ., 2019). To determine whether this is also true in rice, we compared the physiological, transcriptomic and biochemical responses of rice plants to $\mathrm{Zn}$ deprivation and excess 3, 14 and 21 days after the onset of treatment (DAT) to identify links with the regulation of $\mathrm{Mn}, \mathrm{Fe}, \mathrm{Cu}, \mathrm{Ca}$ and $\mathrm{Mg}$. We focused on transcriptional regulators, metal chelators and transporters, ROS-dependent transcriptional reprogramming and the effect of $\mathrm{Zn}$ on secondary metabolism and defense responses.

\section{Materials and Methods}

\section{Plant materials and $\mathrm{Zn}$ treatments}

The rice line selected for this study (Oryza sativa L. cv. Kitaake) was chosen because its short life cycle (9 weeks) is particularly suitable for functional genomics experiments (Jain et al ., 2019). Seeds were surface sterilized with $1.25 \% \mathrm{NaOCl}$ for $60 \mathrm{~min}$, washed three times with Millipore water, soaked in Millipore water at $37^{\circ} \mathrm{C}$ for $24 \mathrm{~h}$ and germinated on moistened paper towels in the dark at $37^{\circ} \mathrm{C}$ for $38 \mathrm{~h}$. The germinated seeds were sown in full-strength $1 \times$ Kimura B nutrient solution and maintained thereafter in a growth chamber with a 12 -h photoperiod $\left(30 / 25^{\circ} \mathrm{C}\right.$ day/night temperature, light intensity $\left.=220 \mu \mathrm{mol} \mathrm{m}^{-2} \mathrm{~s}^{-1}\right)$. The $1 \times$ Kimura B nutrient solution with normal $\mathrm{Zn}$ comprised $0.36 \mathrm{mM}\left(\mathrm{NH}_{4}\right)_{2} \mathrm{SO}_{4}, 0.18 \mathrm{mM} \mathrm{KNO}_{3}, 0.55 \mathrm{mM}$ $\mathrm{MgSO}_{4}, 0.18 \mathrm{mM} \mathrm{KH}_{2} \mathrm{PO}_{4}, 61.20 \mu \mathrm{M}$ Fe citrate, $0.37 \mathrm{mM} \mathrm{Ca}\left(\mathrm{NO}_{3}\right)_{2}, 2.51 \mu \mathrm{M} \mathrm{H}_{3} \mathrm{BO}_{3}, 0.20 \mu \mathrm{M} \mathrm{MnSO}$, $0.2 \mu \mathrm{M} \mathrm{ZnSO}_{4}, 0.05 \mu \mathrm{M} \mathrm{CuSO}_{4}$, and $0.05 \mu \mathrm{M} \mathrm{H}_{2} \mathrm{MoO}_{4}$ (Yoshida, 1976). After 7 days, the seedlings were transferred to full-strength $1 \times$ Kimura B nutrient solution containing three different Zn concentrations: Zn 
deficient $([\mathrm{Zn}]=0.002 \mu \mathrm{M})$, normal $\mathrm{Zn}$ control $([\mathrm{Zn}]=0.2 \mu \mathrm{M})$ and excess $\mathrm{Zn}([\mathrm{Zn}]=300 \mu \mathrm{M})$. During the treatment phase, the nutrient solution was changed every other day. Root and shoot samples were harvested separately at 3, 14 and 21 DAT for physiological, gene expression and biochemical analysis.

\section{Physiological measurements}

We recorded shoot height, root length, fresh weight (FW), dry weight (DW) and (relative) chlorophyll content at 3, 14 and 21 DAT from four biological replicates of 4-10 plants. The relative chlorophyll content in the leaves was measured with a SPAD 502 Plus chlorophyll meter (Spectrum Technologies, USA). For each plant, SPAD measurements were taken from three different points on the fully extended youngest leaf and the mean value was calculated. The chlorophyll $a / b$ content was also measured at 3,14 and 21 DAT using a SpectraMax ABS Plus microplate reader (Molecular Devices, USA) (Wintermans \& De Mots, 1965). We ground $45-50 \mathrm{mg}$ of the fully extended youngest leaf of each plant to homogeneity in $2 \mathrm{~mL} 50 \mathrm{mM}$ sodium phosphate buffer $(\mathrm{pH} 6.8)$ at $4^{\circ} \mathrm{C}$. We mixed a $40 \mu \mathrm{L}$ aliquot of the leaf extract with $960 \mu \mathrm{L} 100 \%$ ethanol in a $1.5 \mathrm{~mL}$ tube before incubating the mixture at $4^{\circ} \mathrm{C}$ in the dark for $30 \mathrm{~min}$. After centrifugation at $1000 \mathrm{~g}$ for 15 min at $4^{\circ} \mathrm{C}, 800 \mu \mathrm{L}$ of the supernatant was transferred to a quartz cuvette for absorbance measurements at 665 and $649 \mathrm{~nm}$. The mean value for each sample was derived from four biological replicates and three technical replicates, and the chlorophyll concentration/content was calculated as previously described (Wintermans \& De Mots, 1965).

\section{Library preparation for transcriptome sequencing}

Total RNA was isolated from root and shoot tissues using the Direct-zol RNA MiniPrep Kit (Zymo Research, USA) with two plants pooled as one biological replicate and three biological replicates per treatment or tissue. RNA concentration and purity were checked on a SimpliNano spectrophotometer (Biochrom, USA) to confirm samples fell within the ranges $\mathrm{OD}_{260} / \mathrm{OD}_{280}=1.8-2.2$ and $\mathrm{OD}_{260} / \mathrm{OD}_{230}$ [?] 2.0. RNA integrity and purity were determined by agarose gel electrophoresis (to confirm the presence of the $4.5-\mathrm{kb} 28 \mathrm{~S}$ rRNA and 1.9-kb $18 \mathrm{~S}$ rRNA bands). RNA integrity and concentration were also assessed using an Agilent 2100 Bioanalyzer (Agilent Technologies, USA) to confirm a RIN value [?] 8.2). We then used $1 \mu \mathrm{g}$ of total RNA per sample for the preparation of each sequencing library using the KAPA mRNA HyperPrep Kit (Roche, Switzerland) following manufacturer's protocol. Briefly, mRNA was captured from total RNA using magnetic oligo-dT beads and was fragmented to a mean library insert size of 100-200 bp by incubation for 8 min at $94^{\circ} \mathrm{C}$ in the presence of $\mathrm{Mg}^{2+}$. First-strand cDNA was synthesized with random hexamer primers followed by secondstrand cDNA synthesis (including dUTP markers), 3' polyadenylation of both strands and adaptor ligation via complementary 3' dTMP overhangs. The library fragments were size selected (300-400 bp) and amplified by PCR with the dUTP-marked strands excluded, allowing strand-specific sequencing. The amplified library was purified and quality checked using the Qsep100 DNA/RNA Analyzer (BiOptic, Taiwan). We prepared 18 RNA sequencing (RNA-Seq) libraries (two tissues $\mathrm{x}$ three $\mathrm{Zn}$ concentrations $\mathrm{x}$ three biological replicates) for sequencing (Biotools, Taiwan) on the NovaSeq 6000 platform (Illumina, USA).

\section{Bioinformatics analysis of transcriptomic data}

Post-sequencing, paired-end raw reads were retrieved in FASTQ format. FastQC and MultiQC were used to check the quality of the raw reads (Ewels, Magnusson, Lundin \& Kaller, 2016). Read trimming steps, including adapter clipping and the removal of low-quality reads and bases, were applied using Trimmomatic v0.38 to obtain high-quality reads (Bolger, Lohse \& Usadel, 2014). High-quality read pairs from each sample were mapped to the Oryza sativa Nipponbare IRGSP-1.0 reference genome using HISAT2 v2.1.0 (Kawahara et al ., 2013; Kim, Langmead \& Salzberg, 2015). FeatureCounts v1.6.0 was used to count reads mapped to annotated genes in the reference genome (Liao, Smyth \& Shi, 2014). To assess variation between samples, principal component analysis (PCA) scatter plots were generated with $\log (\mathrm{FPKM}+1)$ (fragments per kilobase million) normalized reads using the prcomp function and ggplot2 package in $\mathrm{R}$ (Reimers \& Carey, 2006; Wickham, 2016). The DESeq2 package in $\mathrm{R}$ was used to normalize the read counts into "Relative Log Expression" before the identification of differentially expressed genes (DEGs) between two sample groups (Love, Huber \& Anders, 2014). DEGs were defined based on two criteria: (i) the average normalized 
expression of three biological replicates recorded a $\mid \log _{2}$ fold change| [?]1 between two sample groups, and (ii) the Benjamini-Hochberg adjusted p-value was $<0.05$. Functional Gene Ontology (GO) enrichment and pathway mapping analysis was performed on the DEGs identified by comparing the Zn deficiency/excess samples using agriGO v2.0 (Tian et al ., 2017) and MapMan (Thimm et al ., 2004), respectively. Heat maps showing fold changes in expression were generated using the heatmap.2 function of the gplots package in $\mathrm{R}$ (Warnes et al ., 2005).

\section{Validation of DEGs by quantitative reverse transcription PCR (RT-qPCR)}

Total RNA was isolated and quality checked as described above. For each sample, $1 \mu \mathrm{g}$ of total RNA was reverse transcribed using the iScript cDNA Synthesis Kit (Bio-Rad, USA) and the first-strand cDNA was diluted $5 \times$ with Millipore water. Quantitative PCR (qPCR) was carried out on a CFX Connect Real-Time PCR Detection System (Bio-Rad) using iQ SYBR Green Supermix (Bio-Rad). We mixed $3 \mu \mathrm{L}$ PCR-grade water, $10 \mu \mathrm{L} 2 \times \mathrm{iQ}$ SYBR Green Supermix, $1 \mu \mathrm{L} 10 \mu \mathrm{M}$ forward primer, $1 \mu \mathrm{L} 10 \mu \mathrm{M}$ reverse primer and $5 \mu \mathrm{L}$ cDNA. We used primers that passed the primer efficiency test as shown in Table S1. Each reaction comprised an initial denaturation at $95^{\circ} \mathrm{C}$ for $3 \mathrm{~min}$, followed by 40 cycles of $95^{\circ} \mathrm{C}$ for $10 \mathrm{~s}$ and $60^{\circ} \mathrm{C}$ for $30 \mathrm{~s}$. Melting curves were generated to confirm primer specificity. Transcript levels in each sample were measured in four biological replicates (four plants were pooled per replicate) and the mean value was calculated from three technical repeats. The fold difference in expression was calculated using the $2^{-\Delta \Delta^{*} \tau}$ method (Livak \& Schmittgen, 2001). Although four housekeeping genes (OsUbi1 , OsUBQ5 , $\epsilon E \Phi 1 a$ and 18 SrRNA ) were tested in this study, we chose OsUbi1 (rice polyubiquitin) as the reference gene because it achieved the highest stability, lowest coefficient of variance and lowest M value (Mathur, 2014).

\section{Elemental analysis}

Root and shoot tissues were harvested separately for elemental analysis as previously described (Lin et al ., 2009). Briefly, the harvested tissues were washed with ice-cold $10 \mathrm{mM} \mathrm{CaCl}_{2}$ and Millipore water before drying at $70^{\circ} \mathrm{C}$ for 3 days. The dried samples were cut into fine pieces and digested with $0.5 \mathrm{~N} \mathrm{HNO}_{3}$. Multi-element analysis was carried out by inductively coupled plasma-optical emission spectrometry (ICPOES) using an OPTIMA 5300 device (Perkin-Elmer, USA). Concentrations of elements in rice tissues were measured in four biological replicates (four plants were pooled per biological replicate).

\section{Histochemical detection of hydrogen peroxide and superoxide}

Hydrogen peroxide $\left(\mathrm{H}_{2} \mathrm{O}_{2}\right)$ and superoxide $\left(\mathrm{O}_{2}{ }^{-}\right)$in rice leaves were detected by 3,3-diaminobenzidine (DAB) and nitroblue tetrazolium (NBT) staining, respectively. The staining solutions were prepared immediately before the experiments as recommended (Bournonville \& Diaz-Ricci, 2011; Daudi \& O'Brien, 2012). The fully-extended youngest leaves of rice plants in different $\mathrm{Zn}$ treatment groups were cut into two fragments, 2 $\mathrm{cm}$ in length, from the tip of the leaf blade. The fragments were immersed in $3 \mathrm{~mL}$ of staining solution and then infiltrated under vacuum for $5 \mathrm{~min}$. The plates containing tissue samples were placed under light for 12-16 h. For clearer visualization, the leaf fragments were immersed in boiling 95\% ethanol for 10-20 min to remove chlorophyll. Images of four biological replicates were captured against a plain white background.

\section{Measurement of antioxidant enzyme activity}

The activities of ascorbate peroxidase (APX), catalase (CAT) and glutathione reductase (GR) were measured as previously described (Foster \& Hess, 1980; Nakano \& Asada, 1981; Kato \& Shimizu, 1987). For protein extraction, $0.04 \mathrm{~g}$ of finely-ground leaf material in a $10 \mathrm{~mL}$ Falcon tube was mixed with $4 \mathrm{~mL} 50 \mathrm{mM}$ sodium phosphate buffer ( $\mathrm{pH}$ 6.8) and centrifuged at $12000 \mathrm{~g}$ for $20 \mathrm{~min}$ at $4^{\circ} \mathrm{C}$. The supernatant containing the protein extract was transferred to a fresh $2 \mathrm{~mL}$ tube for protein quantification using the Bradford method (Bradford, 1976) and the three antioxidant enzyme assays described below.

APX activity was measured as described by Nakano and Asada (1981). The reagents were added to a disposable cuvette in the following sequence: $1 \mathrm{~mL} 150 \mathrm{mM}$ potassium phosphate buffer (pH 7.0), $1 \mathrm{~mL} 1.5$ $\mathrm{mM}$ ascorbate (prepared fresh), $0.4 \mathrm{~mL} 0.75 \mathrm{mM}$ EDTA, $0.5 \mathrm{~mL} 6 \mathrm{mM} \mathrm{H}_{2} \mathrm{O}_{2}$ (prepared fresh) and $0.1 \mathrm{~mL}$ protein extract. The cuvette was inverted to mix before measuring the absorbance at $290 \mathrm{~nm}$ for 1 min, with 
Millipore water used as the blank. APX activity was calculated using the following formula: APX activity (units $/ \mathrm{mg}$ protein) $=\Delta \mathrm{A}_{290} \times 3$ (total assay volume in $\left.\mathrm{mL}\right) \times 40$ (dilution factor) $\div 2.8$ (absorbance coefficient, $\left.\mathrm{mM}^{-1} \mathrm{~cm}^{-1}\right) \div 1(\mathrm{~min}) \div$ protein content $(\mathrm{mg})$, where 1 unit is defined as $1 \mu \mathrm{mol}$ of ascorbate consumed per minute.

CAT activity was measured as described by Kato and Shimizu (1987). The reagents were added to a quartz cuvette in the following sequence: $2.7 \mathrm{~mL} 100 \mathrm{mM}$ sodium phosphate buffer $(\mathrm{pH} 7.0), 0.1 \mathrm{~mL} 1 \mathrm{M}$ $\mathrm{H}_{2} \mathrm{O}_{2}$ (prepared fresh) and $0.2 \mathrm{~mL}$ protein extract. The cuvette was inverted to mix before measuring the absorbance at $240 \mathrm{~nm}$ for $1 \mathrm{~min}$, with Millipore water was used as the blank. CAT activity was calculated using the following formula: CAT activity (units/mg protein) $=\Delta \mathrm{A}_{240} \times 3$ (total assay volume in $\left.\mathrm{mL}\right) \times$ 20 (dilution factor) $\div 40$ (extinction coefficient, $\left.\mathrm{mM}^{-1} \mathrm{~cm}^{-1}\right) \div 1(\mathrm{~min}) \div$ protein content $(\mathrm{mg})$, where 1 unit is defined as $1 \mathrm{nmol} \mathrm{H}_{2} \mathrm{O}_{2}$ consumed per minute.

GR activity was measured as described by Foster and Hess (1980). The reagents were added to a disposable cuvette in the following sequence: $1 \mathrm{~mL} 150 \mathrm{mM}$ Tris-HCl buffer $(\mathrm{pH} 7.5), 0.3 \mathrm{~mL} 30 \mathrm{mM} \mathrm{MgCl}_{2}, 0.5 \mathrm{~mL}$ $3 \mathrm{mM}$ GSSG (prepared fresh), $1 \mathrm{~mL} 0.45 \mathrm{mM}$ NADPH (prepared fresh) and $0.2 \mathrm{~mL}$ protein extract. The cuvette was inverted to mix before measuring the absorbance at $340 \mathrm{~nm}$ for $1 \mathrm{~min}$, with Millipore water was used as the blank. GR activity was calculated using the following formula: GR activity (units/mg protein) = $\Delta \mathrm{A}_{340} \times 40$ (dilution factor) $\div 1$ (min) $\div$ protein content $(\mathrm{mg}$ ), where 1 unit is defined as $1 \mathrm{nmol} \mathrm{NADPH}$ oxidized per minute.

The final value for each sample was the mean of four biological replicates each comprising three technical replicates.

\section{Statistical analysis}

Statistical analysis was carried out using the lsmeans, multcomp and ggplot2 packages in R (Hothorn, Bretz \& Westfall, 2008; Lenth, 2016; Wickham, 2016). We carried out two-way or three-way analysis of variance (ANOVA) as appropriate, followed by Tukey's post hoc test with different letters denoting a significant difference at $\mathrm{p}<0.05$.

\section{Results}

\section{Zn deficiency and excess delay the growth of rice seedlings}

To determine the physiological changes in rice seedlings under Zn stress, we exposed seedlings to three different $\mathrm{Zn}$ treatments: $\mathrm{Zn}$ deficient $([\mathrm{Zn}]=0.002 \mu \mathrm{M})$, normal $\mathrm{Zn}([\mathrm{Zn}]=0.2 \mu \mathrm{M})$ and excess $\mathrm{Zn}([\mathrm{Zn}]$ $=300 \mu \mathrm{M}$ ). We recorded the responses at 3, 14, and 21 DAT (Figure 1). We observed no morphological changes at 3 DAT but root and shoot growth was delayed under both Zn deprivation and excess, resulting in shorter plants at 14 and 21 DAT (Figure 1A; Figure S1A). The roots were first to sense the Zn status, with the length, FW and DW progressively affected by the duration of treatment (Figure 1B, C; Figure S1B). A similar trend was observed for shoot height, FW and DW (Figure 1D, E; Figure S1C).

The Zn-deficient plants were also characterized by shorter leaf blades than controls, whereas the plants exposed to excess Zn displayed interveinal chlorosis near the leaf tip. The treatments had opposing effects on total chlorophyll levels at 14 DAT, with the Zn-deficient plants accumulating chlorophyll but excess Zn causing the loss of chlorophyll compared to control plants (Figure 1F). However, continued Zn starvation also resulted in the depletion of chlorophyll so that by 21 DAT both the Zn-deprived plants and those exposed to excess Zn had lower total chlorophyll levels than the control plants. This result was corroborated by the SPAD analysis and individual levels of chlorophylls $a$ and $b$ (Figure S1D-F).

To determine whether the $\mathrm{Zn}$ treatments affected $\mathrm{Zn}$ uptake and accumulation, we also measured the concentration of $\mathrm{Zn}$ in the roots and shoots. In plants exposed to excess $\mathrm{Zn}$, the metal began to accumulate in both the roots and shoots by 3 DAT, and increased further with prolonged treatment at 14 and 21 DAT (Figure 
$1 \mathrm{G}, \mathrm{H})$. Even at $3 \mathrm{DAT}$, the Zn concentration in the shoots was well above the $400 \mathrm{mg} / \mathrm{kg}$ DW previously reported as critical toxicity (Silva et al ., 2014). On the other hand, Zn deficiency did not significantly reduce Zn concentrations in the roots or shoots (Figure 1G, H) but there was a slight decline, enough for the concentration in the shoots of Zn-deprived plants to fall below the previously reported $15 \mathrm{mg} / \mathrm{kg} \mathrm{DW}$ critical deficiency concentration (Shanmugam, Tsednee \& Yeh, 2012) at 14 and 21 DAT (Figure 1G). The observed physiological changes are therefore likely to reflect the intracellular Zn concentrations caused by Zn deprivation and excess, respectively.

RNA-Seq analysis reveals DEGs involved in metal ion homeostasis as a response to Zn deficiency or Zn toxicity

The $\mathrm{Zn}$ levels in the shoots and roots suggested that regulatory mechanisms are activated in response to Zn stress at 3 DAT, in agreement with several transcriptome-level studies of nutritional deficiency (Yang, Lin \& Schmidt, 2010; Rodríguez-Celma et al ., 2013; Zhanget al ., 2017). We therefore collected root and shoot tissues at 3 DAT from the three different Zn treatment groups for RNA-Seq analysis. The mapped reads data for all 18 samples are shown in Table S2. The total reads per sample ranged from 37 million to 58 million. We mapped an average of 40,333,876 reads per sample (93.7\%) to the reference genome, 38,946,803 of which (90.5\%) mapped to a single genomic locus and were defined as uniquely mapped reads. The high percentage of uniquely mapped reads confirmed the quality of the samples.

PCA was carried out to evaluate variation among the samples (Figure S2). All 18 samples passed this assessment because the three biological replicates from each treatment were clustered together due to their relatively small variation. The first principal component ( $\mathrm{PC} 1$, explaining $22.2 \%$ of the variance) separated shoot from root samples, indicating that the two tissues were characterized by distinct transcriptomic profiles. The second principal component (PC2, explaining $7.8 \%$ of the variance) separated root samples from different Zn treatment groups, indicating that the root transcriptome is more strongly affected by Zn levels than the shoot.

DEGs were compared in six groups (Table 1). The first four groups compared $\mathrm{Zn}$ deficiency (-Zn) or excess $\mathrm{Zn}(+\mathrm{Zn})$ with normal Zn $(\mathrm{NZn})$ in roots $(\mathrm{R})$ or shoots $(\mathrm{S}):-\mathrm{Zn} / \mathrm{NZn} \_\mathrm{R},-\mathrm{Zn} / \mathrm{NZn} \_\mathrm{S},+\mathrm{Zn} / \mathrm{NZn} \_\mathrm{R}$ and $+\mathrm{Zn} / \mathrm{NZn} \_\mathrm{S}$. In agreement with $\mathrm{PC} 2$, roots from the $+\mathrm{Zn} / \mathrm{NZn}$ comparison showed a higher number of DEGs (820) than the corresponding shoots (163 DEGs). However, the -Zn/NZn comparison yielded similar numbers of DEGs in each tissue: 188 in roots, 186 in shoots (Table 1). The remaining two groups compared -Zn and $+\mathrm{Zn}$ in roots and shoots: $-\mathrm{Zn} /+\mathrm{Zn} \_\mathrm{R}$ and $-\mathrm{Zn} /+\mathrm{Zn} \_\mathrm{S}$. This comparison was required to identify Zn-responsive genes that might fail to meet the $\mid \log _{2}$ fold change| [?] 1 threshold in comparison with normal Zn conditions. For comprehensive analysis, we investigated 723 DEGs from the $-\mathrm{Zn} /+\mathrm{Zn} \_\mathrm{R}$ comparison and 287 from the $-\mathrm{Zn} /+\mathrm{Zn} \_\mathrm{S}$ comparison in more detail (Table 1; Figure $2 \mathrm{~A}$ ).

GO enrichment analysis of the $-\mathrm{Zn} /+\mathrm{Zn}$ DEGs (Figure 2A) revealed several important biological processes affected by Zn treatments: (i) ion and oligopeptide transport, (ii) protection against ROS, (iii) primary metabolism (fatty acids, polysaccharides and amines), and (iv) secondary metabolism linked to defense responses (Figure 2B). The cellular component annotation showed that 197 DEGs were associated with cytoplasmic membrane-bound vesicles (Figure 2B). Interestingly, the molecular function annotation revealed DEGs encoding proteins that bind Fe, $\mathrm{Ca}$ and $\mathrm{Mg}$ ions (Figure 2B; Table S3A, B, C). These proteins were notable because they were also overrepresented in the biological processes related to ROS, secondary metabolism and defense, which are pertinent to Zn deficiency and Zn toxicity responses (Table S3D, E, F).

\section{The expression of $O s Z I P$ genes is induced by $\mathrm{Zn}$ deficiency but suppressed by excess Zn}

F-bZIP transcription factors that mediate Zn-deficiency responses in Arabidopsis are conserved in rice (Lilay et al ., 2020a). To enhance Zn uptake and transport under Zn-deficiency conditions, the rice F-bZIP proteins may induce the expression of OsZIP transporter genes by binding to the ZDRE motifs (RTGTCGACAY) in the corresponding promoters (Lilay et al ., 2020a). We therefore analyzed the expression profiles of OsZIP 
and F-OsbZIP genes by RT-qPCR to confirm the RNA-Seq data at 3, 14 and 21 DAT (Figure 3). Among the 16OsZIP genes in the RNA-Seq dataset, five (OsZIP4,OsZIP5, OsZIPr , OsZIP8 and OsZIP9) were upregulated by Zn deprivation but downregulated by excess Zn at 3 DAT (Figure 3A). The expression of OsZIP4 , OsZIP5 ,OsZIPr and OsZIP8 at 3 DAT was validated by RT-qRCR, and consistent patterns were observed at 14 and 21 DAT (Figure 3C). However, the expression of their upstream regulatory genes $(O s b Z I P 48, O s b Z I P 49$ and OsbZIP50 ) was not significantly altered by either Zn deprivation or excess at 3 DAT (Figure 3B). RT-qPCR confirmed the unchanged level of OsbZIP 48 and OsbZIP50 expression at 3 DAT, whereas OsbZIP 49 expression in shoots was induced by Zn deprivation but suppressed by excess Zn (Figure 3D). At 14 and $21 \mathrm{DAT}$, the expression of these OsbZIP genes was generally repressed by both $\mathrm{Zn}$ treatments, although OsbZIP 49 was induced in the shoots of Zn-deficient plants at 21 DAT (Figure 3D).

\section{Divalent nutrient cations in shoots gradually accumulate in response to $\mathrm{Zn}$ defi- ciency}

Transcriptome profiling also revealed changes in the expression of genes involved in the homeostatic regulation of other nutrient cations. We identified 17 DEGs encoding ion transporters or homeostatic proteins at 3 DAT (Figure 2B, 4A; Table S3G). This was substantiated by the MapMan transport annotation of root DEGs (Figure 4B; Table S4). For example, the expression of $\mathrm{Na}^{+}$and $\mathrm{K}^{+}$transporter genes (Os04g0607600 and Os06g0701700) was induced in the roots of Zn-deficient plants at 3 DAT (Figure 4A; Table S3G). Conversely, genes encoding $\mathrm{Mn}^{2+}$ (OsNRAMP1 ; Os07g0258400) and phosphate (Os08g0564000) transporters, an ironrelated bHLH transcription factor 2 (Os01g0952800), and a $\mathrm{Ca}^{2+} /$ calmodulin domain containing protein (Os07g0633400) were downregulated in the roots of Zn-deficient plants at 3 DAT (Figure 4A; Table S3G, S4). In shoots, $\mathrm{Zn}$ deprivation induced the expression of a $\mathrm{Na}^{+} / \mathrm{H}^{+}$transporter gene (Os05g0382200) but suppressed a $\mathrm{Cu}^{2+}$ transporter gene (Os01g0770700) compared to plants exposed to excess Zn (Figure 4A; Table S3G). Overall, these data show that many genes involved in $\mathrm{Ca}, \mathrm{Na}, \mathrm{K}, \mathrm{Mn}, \mathrm{Fe}$ and $\mathrm{P}$ nutrient transport were modulated in response to $\mathrm{Zn}$ stress.

Metals ions in plant tissues form complexes with ligands such as amino acids, oligopeptides and organic acids, for internal transport and storage (Verbruggen, Hermans \& Schat, 2009). In addition to metal transporters, MapMan analysis also identified several DEGs encoding oligopeptide and amino acid transporters (Figure 4B; Table S4). Most were upregulated by excess Zn, including genes encoding proton-dependent oligopeptide transport (POT) family proteins (Os01g0871600, Os10g0109900, Os10g0148400 and Os01g0871500), an amino acid transporter (Os04g0201800), and oligopeptide transporters of the YELLOW STRIPE LIKE (YSL) family (Os02g0650300 and Os02g0649900). Genes required for the biosynthesis of these ligands were also affected: for example, the OsNAS1 gene encoding nicotianamine synthase 1 (Os03g0307300) andOsNAS2 (Os03g0307200) were upregulated in roots by excess Zn at 3 DAT but OsNAS3 (Os07g0689600) was downregulated (Figure 4A; Table S3G). OsNAS3 is more likely to be induced by Zn deprivation so its expression was validated by RT-qPCR along with the OsNAAT1 gene encoding nicotianamine aminotransferase because both are involved in the synthesis of mugineic acid phytosiderophores (Suzuki et al ., 2006). OsNAS3 and OsNAAT1 were generally induced by Zn deficiency but repressed by excess $\mathrm{Zn}$ at all three time points (Figure $4 \mathrm{C}$ ). The differential expression of genes responsible for ligand biosynthesis and metal-ligand transport is therefore likely to affect the availability and accumulation of metal nutrients in rice plants.

To confirm that $\mathrm{Zn}$ treatments influence the homeostasis of other nutrient ions in rice, we determined the concentrations of relevant macronutrients $(\mathrm{P}, \mathrm{Na}, \mathrm{Ca}, \mathrm{K}$ and $\mathrm{Mg}$ ) and micronutrients $(\mathrm{Mn}, \mathrm{Fe}$ and $\mathrm{Cu})$ in the roots and shoots of rice plants under different Zn treatments at 3, 14 and 21 DAT (Figure 4D; Figure S3). In the roots, only Mn, P and Na were affected by Zn treatments (Figure S3A, D, E) but all the tested nutrients except $\mathrm{Na}$ were affected in the shoots (Figure 4D). The concentration changes in shoots allowed us to assign the nutrients to four groups: (1) Fe, $\mathrm{Cu}$ and $\mathrm{Ca}$ only accumulated in response to $\mathrm{Zn}$ deficiency at $21 \mathrm{DAT}$; (2) Mn and $\mathrm{Mg}$ accumulated in response to $\mathrm{Zn}$ deficiency but were depleted by excess $\mathrm{Zn}$ at 14 and 21 DAT; (3) K was depleted by Zn deficiency but increased in response to excess Zn at 14 DAT; and (4) $\mathrm{P}$ accumulated in response to both treatments at 21 DAT (Figure 4D). The translocation rate of these 
nutrients supported the observed concentration changes in the shoots (Figure S4). For example, in the first group, the enhanced translocation of Fe and Ca due to Zn deficiency at 21 DAT contributed to their elevated shoot concentrations (Figure S4B, F). Similarly, for the second group, the translocation rates of Mn and Mg mirrored their shoot concentrations at 21 DAT, when both increased in response to $\mathrm{Zn}$ deficiency but were depleted in the presence of excess $\mathrm{Zn}$ (Figure S4A, H). We evaluated the crosstalk between Fe, Ca, Mg and $\mathrm{Zn}$ in more detail because GO enrichment identified DEGs encoding proteins that bind to these divalent cations (Figure 2B).

The transcription of genes encoding Fe/Ca-binding peroxidases and the activity of APX in rice leaves are induced by Zn deficiency

Based on GO molecular function enrichment analysis, 44 DEGs encoding Fe-binding proteins and 22 encoding Ca-binding proteins were identified in the $-\mathrm{Zn} /+\mathrm{Zn}$ comparison at 3 DAT (Figure 2B). To visualize the response to $\mathrm{Zn}$ treatments, we generated heat maps showing the fold change in expression (Figure 5A; Figure S5). Interestingly, 14 of the 44 genes encoding Fe-binding proteins (Figure 5A) and 13 of the 22 genes encoding Ca-binding proteins (Figure S5) were peroxidase genes. The 13 Ca-binding peroxidases completely overlapped with the 14 Fe-binding peroxidases (Table S3A, B) and were coordinately regulated in response to Zn stress (Figure 5A; Figure S5). Given that Zn deficiency markedly increased the shoot concentrations of $\mathrm{Fe}$ and $\mathrm{Ca}$ at $21 \mathrm{DAT}$, we hypothesized that some of the peroxidase genes were induced in rice shoots that accumulate modest levels of Fe and Ca during the early stage of Zn deficiency (Figure 4D). In the shoots, Zn deficiency caused modest increases in Fe levels at 3 and 14 DAT, and in Ca levels at 14 DAT (Figure 4D).

The presence of peroxidases indicated the potential involvement of ROS detoxification during Zn deficiency, so we tested leaf tissues from the three treatment groups for the presence of ROS and antioxidant enzyme activity after 3, 14 and 21 days (Figure $5 \mathrm{~B}, \mathrm{C}, \mathrm{D}$; Figure $\mathrm{S} 6$ ). At 3 DAT, DAB staining showed that $\mathrm{H}_{2} \mathrm{O}_{2}$ had not accumulated in the leaves of Zn-deficient plants or those exposed to excess Zn (Figure S6A), but more $\mathrm{H}_{2} \mathrm{O}_{2}$ was present in the leaves exposed to excess $\mathrm{Zn}$ at 14 and 21 DAT (Figure 5B; Figure S6C). NBT staining to detect $\mathrm{O}_{2}{ }^{-}$yielded comparable results (Figure 5C; Figure S6B, D). The elimination of ROS involves enzymes such as APX, CAT and GR, which reduce oxidative stress (Cakmak, 2000). CAT and GR activity in shoots was generally reduced by excess Zn at 14 and 21 DAT, but there was no effect on the activity of APX (Figure 5D). Interestingly, although CAT activity in the shoots was reduced in response to Zn deficiency at 14 and 21 DAT, the opposite profile was observed for APX, which showed higher activity at these time points (Figure 5D).

In summary, these data show that early $\mathrm{Zn}$ deficiency leads to the modest accumulation of $\mathrm{Fe}$ and $\mathrm{Ca}$ in rice shoots, enhancing the expression of genes encoding $\mathrm{Fe} / \mathrm{Ca}$-binding proteins such as peroxidases to improve oxidative stress tolerance via the removal of $\mathrm{H}_{2} \mathrm{O}_{2}$.

Excess $\mathrm{Zn}$ in rice shoots induces the expression of genes encoding Mg-binding enzymes required for diterpenoid biosynthesis

Finally, we investigated the importance of crosstalk between $\mathrm{Mg}$ and $\mathrm{Zn}$ in rice plants by comparing $\mathrm{Mg}$ levels and Mg-related DEGs. In the presence of excess Zn, the concentration of Mg in rice shoots decreased slightly at 3 DAT, but more severely at 14 and 21 DAT (Figure 4D). GO molecular function enrichment analysis of the $-\mathrm{Zn} /+\mathrm{Z}$ comparison revealed 12 DEGs encoding Mg-binding proteins at 3 DAT (Figure 2B). To visualize the response to $\mathrm{Zn}$ treatments, we generated heat maps showing the fold change in expression. This revealed that most of the genes were suppressed in the roots but induced in the shoots in response to both forms of Zn stress (Figure 6A). Eleven of the genes were related to terpene biosynthesis, eight for the synthesis of diterpenes (Os04g0179700, Os11g0474800, Os04g0178300, Os02g0570400, Os02g0571100, Os04g0612000, Os12g0491800 and Os02g0571300), two for sesquiterpenes (Os03g0362500 and Os08g0167800) and one for monoterpenes (Os04g0340300) (Table S3C). This suggests that the Zn-mediated changes in endogenous Mg levels alter the expression of genes encoding Mg-binding proteins, especially those encoding enzymes involved in terpene biosynthesis.

As an illustration, four genes in the diterpenoid pathway were concomitantly upregulated in shoots exposed 
to excess Zn (Figure 6B; Table S3C). Two genes encoding upstream copalyl diphosphate synthases (OsCPS2 and $\mathrm{OsCPS}_{4}$ ) were induced in shoots by excess $\mathrm{Zn}$ (Figure 6B). At the branching point of this pathway, the former enzyme catalyzes the conversion of geranylgeranyl diphosphate (GGPP) to ent -copalyl diphosphate (ent-CPP), and the latter enzyme catalyzes the formation of syn-CPP from the same substrate (Figure 6B). In the ent-CPP branch, the expression of a gene encoding ent -kaurene synthase-like enzyme 7 (OsKSL 7 ) was upregulated by excess Zn (Figure 6B). OsKSL7 catalyzes the synthesis of precursors for phytocassanes A-E (Umemura et al ., 2003). In the syn-CPP branch, the OsKSL4 gene was also induced by excess $\mathrm{Zn}$ (Figure 6B). OsKSL4 catalyzes the formation of precursors for momilactones A and B (Umemura et al ., 2003). Furthermore, the OsKSL8 gene (responsible for the synthesis of a precursor for oryzalexin S) was modulated by excess $\mathrm{Zn}$ with a $0.86 \log _{2}$ fold change in expression (Figure $6 \mathrm{~B}$ ).

Taken together, our results show that excess Zn causes an early, slight decline in Mg levels in rice shoots, enhancing the expression of genes encoding Mg-binding proteins. In the diterpenoid biosynthesis pathway, these proteins are key enzymes responsible for the biosynthesis of two subtypes of important defense-related diterpenoids: momilactones $\mathrm{A}$ and $\mathrm{B}$, and phytocassanes A-E.

\section{Discussion}

In this study, we compared the physiological, transcriptomic and biochemical responses of rice to normal $\mathrm{Zn}$ levels and two forms of $\mathrm{Zn}$ stress (Zn deprivation and excess) at 3, 14 and 21 DAT. The genes encoding Zn transporters $O s Z I P 4 / 5 / 7 / 8 / 9 / 10$ were differentially expressed in response to Zn stress. The levels of $\mathrm{Mn}$ and $\mathrm{Mg}$ in rice shoots mirrored the expression of the OsZIP genes. The accumulation of Fe and $\mathrm{Ca}$ in response to Zn deficiency probably increase the activity of Fe/Ca-binding proteins related to ROS-mediated stress responses. Interestingly, the enhanced expression of genes encoding Mg-binding proteins in response excess $\mathrm{Zn}$ is related to the production of antifungal and other antimicrobial secondary metabolites.

The roles of F-bZIP transcription factors, ZIP transporters, nicotianamine and deoxymugineic acid in the response to Zn deficiency

Two F-bZIP proteins (AtbZIP19 and AtbZIP23) regulate the response to Zn deficiency in Arabidopsis by binding to ZDRE motifs in the promoters of Zn homeostatic genes such as those encoding ZIP transporters and nicotianamine synthase (Assuncao et al ., 2010; Assuncao et al ., 2013). Similar genetic modules are conserved in the response to Zn deficiency in barley, wheat and rice (Castro et al ., 2017; Evenset al ., 2017; Nazri et al ., 2017; Lilay et al ., 2020a). Recently, a complementation experiment showed that the rice F-bZIP transcription factor genes OsbZIP 48 and OsbZIP50 (but not OsbZIP49 ) rescued hypersensitivity to Zn deficiency in the Arabidopsis double mutant bzip19bzip23 (Lilay et al ., 2020a). In our study, the transcript profiles of OsbZIP $48, O s b Z I P 49$ and OsbZIP50 in the roots and shoots of rice plants from different Zn treatment groups at 3,14 and 21 DAT revealed that OsbZIP 48 and OsbZIP50 were not induced by Zn deficiency at the three time points (Figure 3B, D). RNA-Seq analysis suggested that OsbZIP49 was not affected by Zn deficiency at 3 DAT but RT-qPCR verification experiments showed that the gene was induced by Zn deficiency in the shoots at 3 and 21 DAT (Figure 3B, D). With the exception of OsbZIP49, our transcriptional data for F-OsbZIP genes generally agreed with Lilay et al . (2020a), who reported that the transcript levels of these three genes did not increase in response to $\mathrm{Zn}$ deficiency in rice roots or shoots at 21 DAT. In Arabidopsis, the expression of AtbZIP19 and AtbZIP23 was also not significantly increased by Zn deficiency (Assuncao et al ., 2010; Lilay et al ., 2019). Therefore, the regulation of these transcription factors may occur at the post-translational level (Assuncao et al ., 2013; Lilay et al ., 2019). In contrast, genes encoding the wheat F-TabZIP transcription factors (TabZIPF1, TabZIPF3a, TabZIPF3b and TabZIPF4 ) were induced in the roots and shoots of 2-week-old seedlings throughout a Zn deficiency treatment lasting 7 days (Evenset al ., 2017). The contrast between Arabidopsis and wheat suggests that F-bZIP proteins are regulated by different species-dependent mechanisms acting at the transcriptional, post-transcriptional or post-translational levels. 
F-OsbZIP transcription factors are thought to regulate OsZIPgenes to mediate adaptation to Zn deficiency (Assuncao et al ., 2010; Lilay et al ., 2020a). The rice ZIP transporter family, represented by 16 genes, is involved in the transport of various divalent cations, including $\mathrm{Zn}^{2+}$ (Ishimaru et al ., 2005; Tiong et al ., 2015). In this study, the expression ofOsZIP $4 / 5 / 7 / 8 / 9$ in roots and shoots was modulated in opposite directions by Zn deficiency (induction) and excess Zn (suppression) at the three time points (Figure 3A, C). This agrees with a previous study showing that $O s Z I P 4 / 5 / 8$ were induced in rice roots and shoots by $\mathrm{Zn}$ deprivation (Suzuki et al ., 2012). These three OsZIPgenes, expressed individually in yeast, were also able to complement a Zn-dependent growth mutant, confirming they encode functional Zn transporters (Ishimaru et al ., 2005; Yang et al ., 2009; Lee et al ., 2010a; Lee et al ., 2010b). OsZIP7 was also induced in rice roots by $\mathrm{Fe}$ starvation and complemented a yeast mutant deficient for $\mathrm{Fe}$ uptake, confirming it encodes a functional Fe transporter (Yang et al ., 2009). However, another yeast complementation assay indicated that OsZIP7 is an influx transporter for Zn and cadmium (Cd) but not Fe (Tan et al ., 2019). OsZIP7 transports $\mathrm{Zn}$ and $\mathrm{Cd}$ upward in rice via xylem loading in roots and intervascular transfer in nodes (Tan et al ., 2019). Expression data suggest that OsZIP9 is involved in the regulation of Zn homeostasis in shoots (Shao, Xia, Yamaji, Shen \& Ma, 2018), but two more recent studies provide strong evidence that OsZIP9 facilitates $\mathrm{Zn}$ uptake in rice roots during Zn deprivation (Huang et al ., 2020; Tanet al ., 2020). Besides Zn uptake, the synergistic action of OsZIP5 and OsZIP9 (encoded by duplicate genes) also modulates Cd uptake, with OsZIP9 taking on the prominent role (Tan et al ., 2020).

Nicotianamine is required for the chelation and transport of divalent cations, including $\mathrm{Zn}^{2+}$ (Higuchi, Kanazawa, Nishizawa, Chino \& Mori, 1994). The synthesis of nicotianamine from S-adenosylmethionine is catalyzed by nicotianamine synthase (Higuchiet al ., 1994) encoded in rice by three paralogous genes: OsNAS1 , OsNAS2 and OsNAS3 (Higuchi et al ., 2001). The expression of OsNAS1 and OsNAS2 in roots was induced by excess Zn at $3 \mathrm{DAT}$, whereas OsNAS3 expression in roots was reduced by the same treatment (Figure 4A). A previous study showed that OsNAS1 and OsNAS2 were induced in rice roots and leaves in response to Fe deficiency, whereas OsNAS3 was induced in roots but suppressed in leaves (Inoue et al ., 2003). In maize,ZmNAS1 and ZmNAS2 were induced in Fe-deficient roots, whereas ZmNAS3 was suppressed (Mizuno et al ., 2003). Considering all these results together in the context of the well-known negative crosstalk between Fe and Zn (Cakmak, 2000), OsNAS3 appears likely to be involved in the regulation of Zn homeostasis. Indeed, OsNAS3 and OsNAAT1 both encode enzymes required for the synthesis of mugineic acid phytosiderophores, and were induced by $\mathrm{Zn}$ deprivation but repressed by excess $\mathrm{Zn}$ in our experiments (Figure 4C).

Promiscuous Zn transporters and chelators increase the accumulation of multiple divalent cations in rice shoots under Zn deficiency conditions

In this study, the concentrations of $\mathrm{Mn}$ and $\mathrm{Mg}$ in shoots increased in response to $\mathrm{Zn}$ deficiency at 14 and $21 \mathrm{DAT}$, and the concentrations of $\mathrm{Fe}, \mathrm{Cu}$ and $\mathrm{Ca}$ increased at $21 \mathrm{DAT}$ (Figure 4D). The accumulation of these five nutrients in shoots reflected their translocation from roots under $\mathrm{Zn}$ deficiency conditions (Figure S4). To determine the molecular mechanisms underlying this finding, we monitored the dynamic expression profiles of genes annotated by GO enrichment analysis as "ion transport" and by MapMan as "transport" (Figure 4A, B; Table S3G; Table S4).

Both RNA-Seq and RT-qPCR data confirmed the upregulation ofOsZIP4/5/7/8/9, OsNAS3 and OsNAAT1 in response to Zn deficiency at 3, 14 and 21 DAT (Figure 3A, C; Figure 4A, C). We did not observe the induction of any genes encoding $\mathrm{Mn}, \mathrm{Fe}, \mathrm{Cu}, \mathrm{Ca}$ or $\mathrm{Mg}$ transporters in response to $\mathrm{Zn}$ deficiency at $3 \mathrm{DAT}$, but these genes were downregulated in the $-\mathrm{Zn} /+\mathrm{Zn}$ comparison at 3 DAT (Table S3G; Table S4). Therefore, the translocation of nutrients to shoots and their accumulation in response to $\mathrm{Zn}$ deficiency may reflect the activity of OsZIP transporters and Zn chelators, including nicotianamine and deoxymugineic acid. Functional complementation in yeast mutants deficient for metal uptake demonstrated that ZIP transporters bind various divalent cations, including $\mathrm{Zn}^{2+}, \mathrm{Fe}^{2+}, \mathrm{Mn}^{2+}$ and $\mathrm{Cd}^{2+}$ (Guerinot, 2000). Among the transporters identified by our transcriptomic analysis, OsbZIP7 is a functional Fe transporter in rice because it complemented a yeast mutant deficient for Fe uptake (Yang et al ., 2009), and the expression of OsZIP4 was 
influenced by the availability of $\mathrm{Zn}^{2+}, \mathrm{Cu}^{2+}$ and $\mathrm{Mn}^{2+}$ (Ishimaru et al ., 2005).

OsNAS1 and OsNAS2 are induced by Fe starvation butOsNAS3 was recently shown to be induced in various rice tissues in response to excess Fe (Aung et al ., 2019). Similarly, we observed the upregulation of OsNAS3 in rice roots and shoots in response to Zn deficiency (Figure 4C). The accumulation of nicotianamine would increase the chelation and transport of various divalent cations, including $\mathrm{Cu}^{2+}, \mathrm{Ni}^{2+}, \mathrm{Co}^{2+}, \mathrm{Zn}^{2+}, \mathrm{Fe}^{2+}$ and $\mathrm{Mn}^{2+}$ (Higuchi et al ., 1994; Lin \& Aarts, 2012). Furthermore, nicotianamine is also the precursor of deoxymugineic acid (DMA), a mugineic acid phytosiderophore secreted from the roots to chelate $\mathrm{Fe}^{3+}$ in the rhizosphere for subsequent uptake (Suzuki et al ., 2006). We observed the significant upregulation of OsNAAT1 expression in rice shoots in response to Zn deprivation (Figure 4C). YSL transporters interact with metal-phytosiderophore complexes to translocate $\mathrm{Fe}^{3+}, \mathrm{Cu}^{2+}$ and $\mathrm{Mn}^{2+}$, and this could also explain the accumulation of these nutrients in rice shoots under Zn deficiency conditions (Dai et al ., 2018) (Figure $4 \mathrm{D})$.

In summary, to maximize Zn availability in a Zn-deficient rhizosphere, rice plants increase the expression of OsZIP genes, OsNAS3and OsNAAT1. However, the low availability of $\mathrm{Zn}$ in the rhizosphere and the promiscuity of OsZIP transporters and $\mathrm{Zn}$ chelators cause the accumulation of $\mathrm{Mn}, \mathrm{Fe}, \mathrm{Cu}, \mathrm{Ca}$ and $\mathrm{Mg}$, which are translocated to the rice shoots. These five nutrients follow two distinct trends with potential biological significance: (i) the accumulation of $\mathrm{Fe}, \mathrm{Cu}$ and $\mathrm{Ca}$ in shoots increased significantly in response to Zn deficiency at $21 \mathrm{DAT}$; and (ii) $\mathrm{Mn}$ and $\mathrm{Mg}$ accumulated in response to Zn deficiency but were also depleted in the presence of excess Zn at 14 and 21 DAT (Figure 4D).

Modest $\mathrm{Fe}$ and $\mathrm{Ca}$ accumulation in shoots induces gene expression and APX activity to prevent leaf chlorosis caused by Zn deficiency

Our results showed that the expression of genes encoding $\mathrm{Fe} / \mathrm{Ca}$-binding peroxidases was induced in rice shoots during the early phase of Zn deficiency (Figure 4D; Figure 5A; Figure S3B, F). APX activity in the shoots increased in response to Zn deficiency at 14 and 21 DAT, mirroring the accumulation of $\mathrm{H}_{2} \mathrm{O}_{2}$ in leaves (Figure 5B, D). Changes in intracellular $\mathrm{Zn}$ and Fe levels in plants disrupt the balance between ROS production and elimination (Wang \& Jin, 2007; Tripathi et al ., 2018). Zn deficiency (below 15 $\mathrm{mg} / \mathrm{kg}$ DW) and Fe toxicity (400-1000 mg/kg DW) can both increase ROS production in plants (Vose, 1982; Shanmugam et al ., 2012). In addition to their individual effects, the crosstalk between $\mathrm{Zn}$ and Fe also affects ROS levels and the antioxidant system (Shanmugam et al ., 2012). The increase in Fe levels we observed under Zn deficiency conditions (Figure 4D) suggests that the crosstalk triggers further ROS production. An optimal level of $\mathrm{Zn}$ is required for the activity of antioxidant enzymes with $\mathrm{Zn}$ cofactors, which prevent the accumulation of excess ROS (Westin \& Schaffner, 1988; Miller, 2012). Zn deficiency also triggers the ROS accumulation via the membrane-bound $\mathrm{O}_{2}^{-}$-generating $\mathrm{NADPH}$ oxidase (Cakmak \& Marschner, 1988). The accumulation of $\mathrm{Fe}$ in plants increases the generation of ROS through diverse mechanisms (Shahid et al ., 2014). Notably, in the Fenton reaction, $\mathrm{Fe}^{2+}$ reduces $\mathrm{H}_{2} \mathrm{O}_{2}$ to the highly reactive hydroxyl free radical $\mathrm{OH}^{*}$ (Mittler, 2017).

Excessive ROS production is responsible for the typical phenotypes of Zn-deficient plants, such as leaf chlorosis and delayed growth (Wang \& Jin, 2007; Shinozaki et al ., 2020) and we observed the same phenotypes in our study (Figure 1A, Figure S1). A recent model suggests that $\mathrm{OH}^{*}$ produced via the Fe-dependent Fenton reaction is the cause of Zn-deficient leaf chlorosis (Shinozaki et al ., 2020). More importantly, the study showed the importance of autophagy, conferred by a small number of autophagy-related proteins, in salvaging limited $\mathrm{Zn}$ reserves by degrading particular target proteins and organelles. The salvaged $\mathrm{Zn}$ supply is then redistributed to important $\mathrm{Zn}$-binding enzymes such as $\mathrm{Cu} / \mathrm{Zn} \mathrm{SOD}$ in the chloroplasts. Following the redistribution of autophagy-derived $\mathrm{Zn}$, the enzymatic activity of $\mathrm{Cu} / \mathrm{Zn}$ SOD is restored and the chloroplast is protected from damage (Shinozakiet al ., 2020). Our results fit this model because APX scavenges $\mathrm{H}_{2} \mathrm{O}_{2}$, which is produced when $\mathrm{Cu} / \mathrm{Zn}$ SOD catalyzes the dismutation of $\mathrm{O}_{2}{ }^{-}$(Figure $\left.5 \mathrm{~B}, \mathrm{D}\right)$. Otherwise, the accumulation of $\mathrm{H}_{2} \mathrm{O}_{2}$ causes the inhibition and degradation of $\mathrm{Cu} / \mathrm{Zn} \mathrm{SOD}$ (Casano, Gomez, Lascano, Gonzalez \& Trippi, 1997) and leads to the accumulation of $\mathrm{OH}^{*}$ via the Fenton reaction (Mittler, 2017). 
Plants express a number of antioxidant enzymes to remove ROS (SOD, APX, CAT and GR) as well as producing antioxidant metabolites such as ascorbic acid, glutathione and phenolic compounds (Kasote, Katyare, Hegde \& Bae, 2015). Three families of SOD are recognized based on their metal cofactors: $\mathrm{Cu} / \mathrm{Zn}$, $\mathrm{Fe}$ and Mn (Miller, 2012). The $\mathrm{Cu} / \mathrm{Zn}$ SOD family is predominant in higher plants and members are found in the chloroplast and cytosol (Pilon, Ravet \& Tapken, 2011). As expected, given that Zn is one of the cofactors of $\mathrm{Cu} / \mathrm{Zn} \mathrm{SOD}, \mathrm{Zn}$ deficiency reduces the activity of this enzyme (Cakmak \& Marschner, 1993; Wang \& Jin, 2007). The activities of enzymes that scavenge $\mathrm{H}_{2} \mathrm{O}_{2}$ (APX, CAT and GR) are also inhibited by Zn deficiency (Cakmak, 2000). However, higher activities of these antioxidant enzymes have been reported in Zn-efficient wheat and rice plants under Zn deficiency conditions (Cakmak et al ., 1997; Begum et al ., 2016). In the current study, we found that APX activity in shoots increased in response to Zn deficiency at 14 and 21 DAT (Figure 5D), in agreement with the accumulation of $\mathrm{H}_{2} \mathrm{O}_{2}$ in the leaves of Zn-deficient plants at 14 and 21 DAT (Figure 5B; Figure S6C).

The induction of genes encoding Fe/Ca-binding peroxidases after 3 days of Zn deprivation suggests that the higher APX activity we observed may reflect the increased abundance of these enzymes (Figure 5A, D). APX uses $\mathrm{Fe}$ as a cofactor, so the accumulation of this enzyme would sequester free Fe ions as well as scavenging more $\mathrm{H}_{2} \mathrm{O}_{2}$ (Santos et al ., 2019). These dual functions may have led to the evolutionary selection of APX as a response to $\mathrm{Zn}$ deficiency. This might also explain the opposite effects of $\mathrm{Zn}$ deficiency and excess on the total chlorophyll content of rice leaves at 14 DAT, with the content increasing in response to Zn deficiency (Figure $1 \mathrm{~F}$ ). In summary, rice plants starved of Zn begin to accumulate Fe and Ca in the shoots at 3 DAT, leading to the induction of peroxidase genes. This increases the activity of APX in the shoots at 14 and 21 DAT, helping to prevent Zn-deficient leaf chlorosis. However, if the Fe concentration in the shoot increases above the 400-1000 mg/kg DW threshold of critical toxicity during prolonged (e.g., 21 DAT) or severe Zn deficiency stress (Figure 4D), then the response becomes insufficient and chlorosis ensues.

The modest depletion of $\mathrm{Mg}$ in shoots exposed to excess $\mathrm{Zn}$ induces defense-related genes associated with diterpenoid biosynthesis

The growth hormone GA and defense-related phytoalexins and phytoanticipins are derived from the diterpenoid pathway, so the coordinated control of this pathway is needed for the efficient allocation of metabolic resources to growth or defense (Lu et al ., 2018). The pathway branches when GGPP is converted into one of the two stereoisomers ent-CPP and syn-CPP, with GA derived from the former and each branch also giving rise to different phytoalexins/phytoanticipins (Figure 6B). Although GA and defense-related diterpenoids are produced via the ent-CPP route, the rice genome encodes two ent-CPP synthases: OsCPS1 (for GA) and OsCPS2 (for defense-related diterpenoids). These allow the coordinated modulation of growth and defense in rice plants (Hayashiet al ., 2008). Intriguingly, our results suggested that an early response to excess Zn is a slight depletion of intracellular $\mathrm{Mg}$ levels in shoots, which induces the expression of five genes encoding Mg-binding proteins (Figure 4D; Table S3C). Four of these genes (OsCPS4 and OsKSL4 from the syn -CPP branch;OsCPS2 and OsKSL7 from the ent -CPP branch) encode enzymes that synthesize important defense-related diterpenoids: momilactones A and B, and phytocassanes A-E (Figure 6B) (Umemuraet al ., 2003). Given that genes required for GA synthesis (OsCPS1 and OsKS1) were not differentially expressed, we deduce that defense is prioritized in the presence of excess Zn at 3 DAT (Figure 6B).

When exposed to microbial infection, rice plants allocate metabolic resources to the synthesis of diterpenoid phytoalexins, including momilactones $\mathrm{A}$ and $\mathrm{B}$, oryzalexins $\mathrm{A}-\mathrm{F}$, oryzalexin $\mathrm{S}$ and phytocassanes A-E, by inducing the corresponding genes (Lu et al ., 2018). For example, Shimizu et al . (2008) reported that the OsCPS4, OsKSL4, OsCPS2 and OsKSL7 were induced within $12 \mathrm{~h}$ following exposure to a fungal elicitor, leading to the accumulation of momilactones and phytocassanes at 12-48 h. Furthermore, these genes were induced more rapidly when a variety resistant to the rice blast fungusMagnaporthe oryzae was inoculated with the pathogen, resulting in the earlier and stronger accumulation of momilactones A and B, and phytocassanes A-E, in resistant versus susceptible rice leaves (Hasegawaet al ., 2010). Momilactones and phytocassanes also accumulated in rice leaves following infection with the bacterial leaf blight pathogen,Xanthomonas oryzae (Klein et al ., 2015). However, given that the knockdown of OsCPS4 and the overexpression of OsCPS2 
reduces susceptibility to $X$. oryzae infection, phytocassanes are likely to be the most effective phytoalexins against this pathogen (Lu et al ., 2018). OsCPS4 (or thesyn-CPP route) also confers resistance to fungal non-host disease in rice (Lu et al ., 2018). Therefore, our findings could facilitate research aiming to improve the resistance of rice against microbial infection by Zn fortification.

\section{Conclusion}

This study has demonstrated the important relationship between $\mathrm{Zn}$ and other divalent nutrient cations (Fe, $\mathrm{Cu}, \mathrm{Ca}, \mathrm{Mn}$ and $\mathrm{Mg}$ ) during $\mathrm{Zn}$ stress in rice (Figure 7). Zn deficiency causes these divalent cations to be translocated to rice shoots due to the increased activity of promiscuous $\mathrm{Zn}$ transporters and chelators. The accumulation of these cations during prolonged Zn deficiency is harmful to rice plants, especially Fe. Therefore, over time, rice plants have evolved to interpret modest changes in cation levels as important signals of early Zn stress. Early detection allows rice plants to respond immediately by reprogramming their transcriptional and metabolic processes. In certain cases, such readjustments serve both to reduce the intracellular levels of cations and mediate important Zn stress responses. Rice plants have achieved this delicate modulation by naturally selecting for the functional clustering of enzymes with the same cofactor. For example, the early detection of increasing Fe and Ca levels in shoots activates the transcription of genes encoding Fe/Ca-binding peroxidases, ultimately promoting the synthesis and activity of APX in the shoots. APX provides a good example of the dual-function metabolic adjustment mentioned above, because the increased availability of this enzyme sequesters $\mathrm{Fe}$ to prevent Fe-induced toxicity in the leaves while scavenging $\mathrm{H}_{2} \mathrm{O}_{2}$ more efficiently during periods of $\mathrm{Zn}$ deprivation to prevent leaf chlorosis. Similarly, the modest depletion of $\mathrm{Mg}$ in the shoots in response to excess $\mathrm{Zn}$ may act as a signal to activate defense-related diterpenoid biosynthesis pathways.

\section{Acknowledgments}

We wish to thank Dr. Yu-Chang Tsai and Chen-Han Jan from the Department of Agronomy, National Taiwan University for generously providing us with the Oryza sativa L. cv. Kitaake seeds.

\section{Author Contributions}

YL conceived and designed the research project. YC, JL, IT conducted the experiments. BC and YL contributed to data interpretation. BC, YC, KY and YL contributed to manuscript preparation. All authors have read and approved the final version of the manuscript.

\section{Conflict of Interest}

The authors declare that the research was conducted in the absence of any commercial or financial relationships that could be construed as a potential conflict of interest.

\section{References}

Andreini C., Banci L., Bertini I. \& Rosato A. (2006). Zinc through the three domains of life. Journal of Proteome Research , 5(11), 3173-3178.

Apel K. \& Hirt H. (2004). Reactive oxygen species: metabolism, oxidative stress, and signal transduction. Annual Review of Plant Biology, 55, 373-399. 
Assuncao A.G., Herrero E., Lin Y.F., Huettel B., Talukdar S., Smaczniak C., . . . Aarts M.G. (2010). Arabidopsis thaliana transcription factors bZIP19 and bZIP23 regulate the adaptation to zinc deficiency.Proceedings of the National Academy of Sciences of the United States of America , 107(22), 1029610301.

Assuncao A.G., Persson D.P., Husted S., Schjorring J.K., Alexander R.D. \& Aarts M.G. (2013). Model of how plants sense zinc deficiency.Metallomics , 5(9), 1110-1116.

Aung M.S., Masuda H., Nozoye T., Kobayashi T., Jeon J.S., An G. \& Nishizawa N.K. (2019). Nicotianamine synthesis by OsNAS3 is important for mitigating iron excess stress in rice. Frontiers in Plant Science, 10, 660.

Bae Y.S., Oh H., Rhee S.G. \& Yoo Y.D. (2011). Regulation of reactive oxygen species generation in cell signaling. Molecules and Cells, 32(6), 491-509.

Bandyopadhyay T., Mehra P., Hairat S. \& Giri J. (2017). Morpho-physiological and transcriptome profiling reveal novel zinc deficiency-responsive genes in rice. Functional and Integrative Genomics , 17(5), 565-581.

Begum M.C., Islam M., Sarkar M.R., Azad M.A.S., Nazmul Huda A.K.M. \& Kabir, A.H. (2016). Auxin signaling is closely associated with Zn-efficiency in rice (Oryza sativa L.). Journal of Plant Interactions , 11(1), 124-129.

Bolger A.M., Lohse M. \& Usadel B. (2014). Trimmomatic: a flexible trimmer for Illumina sequence data. Bioinformatics , 30(15), 2114-2120.

Bournonville C.F. \& Diaz-Ricci J.C. (2011). Quantitative determination of superoxide in plant leaves using a modified NBT staining method.Phytochemical Analysis , 22(3), 268-271.

Bradford M.M. (1976). A rapid and sensitive method for the quantitation of microgram quantities of protein utilizing the principle of protein-dye binding. Analytical Biochemistry , 72(1-2), 248-254.

Cabot C., Martos S., Llugany M., Gallego B., Tolra R. \& Poschenrieder C. (2019). A role for zinc in plant defense against pathogens and herbivores. Frontiers in Plant Science, 10, 1171.

Cakmak I. (2000). Tansley Review No. 111 Possible roles of zinc in protecting plant cells from damage by reactive oxygen species. The New Phytologist ,146(2), 185-205.

Cakmak I., Ozturk L., Eker S., Torun B., Kalfa H.I. \& Yilmaz A. (1997). Concentration of zinc and activity of copper/zinc-superoxide dismutase in leaves of rye and wheat cultivars differing in sensitivity to zinc deficiency. Journal of Plant Physiology, 151(1), 91-95.

Cakmak I. \& Marschner H. (1988). Zinc-dependent changes in ESR signals, NADPH oxidase and plasma membrane permeability in cotton roots.Physiologia Plantarum , 73(1), 182-186.

Cakmak I. \& Marschner H. (1993). Effect of zinc nutritional status on activities of superoxide radical and hydrogen peroxide scavenging enzymes in bean leaves. Plant and Soil , 155, 127-130.

Casano L.M., Gomez L.D., Lascano H.R., Gonzalez C.A. \& Trippi V.S. (1997). Inactivation and degradation of CuZn-SOD by active oxygen species in wheat chloroplasts exposed to photooxidative stress. Plant and Cell Physiology , 38(4), 433-440.

Castro P.H., Lilay G.H., Munoz-Merida A., Schjoerring J.K., Azevedo H. \& Assuncao A.G.L. (2017). Phylogenetic analysis of F-bZIP transcription factors indicates conservation of the zinc deficiency response across land plants. Scientific Reports , 7, 3806 .

Clemens S. (2001). Molecular mechanisms of plant metal tolerance and homeostasis. Planta , 212(4), 475-486.

Dai J., Wang N., Xiong H., Qiu W., Nakanishi H., Kobayashi T., . . Z Zuo Y. (2018). The Yellow Stripe-Like (YSL) gene functions in internal copper transport in peanut. Genes, 9(12), 635. 
Daudi A. \& O'Brien J.A. (2012). Detection of hydrogen peroxide by DAB staining in Arabidopsis leaves. Bio-protocol , 2(18), e263.

Eide D.J. (2011). The oxidative stress of zinc deficiency.Metallomics , 3(11), 1124-1129.

Evens N.P., Buchner P., Williams L.E. \& Hawkesford M.J. (2017). The role of ZIP transporters and group F bZIP transcription factors in the Zn-deficiency response of wheat (Triticum aestivum). The Plant Journal , 92(2), 291-304.

Ewels P., Magnusson M., Lundin S. \& Kaller M. (2016). MultiQC: summarize analysis results for multiple tools and samples in a single report. Bioinformatics , 32(19), 3047-3048.

Feigl G., Lehotai N., Molnar A., Ordog A., Rodriguez-Ruiz M., Palma J., . . . Kolbert Z. (2015). Zinc induces distinct changes in the metabolism of reactive oxygen and nitrogen species (ROS and RNS) in the roots of two Brassica species with different sensitivity to zinc stress.Annals of Botany , 116(4), 613-625.

Foster J.G. \& Hess J.L. (1980). Responses of superoxide dismutase and glutathione reductase activities in cotton leaf tissue exposed to an atmosphere enriched in oxygen. Plant Physiology , 66(3), 482-487.

Guerinot M.L. (2000). The ZIP family of metal transporters.Biochimica et Biophysica Acta , 1465(1-2), 190-198.

Hafeez B., Khanif Y.M. \& Saleem M. (2013). Role of zinc in plant nutrition- a review. American Journal of Experimental Agriculture, 3(2), 374-391.

Hasegawa, M., Mitsuhara, I., Seo, S., Imai, T., Koga, J., Okada, K., . . . Ohashi Y. (2010). Phytoalexin accumulation in the interaction between rice and the blast fungus. Molecular Plant-Microbe Interactions, 23(8), 1000-1011.

Hayashi Y., Toyomasu T., Hirose Y., Onodera Y., Mitsuhashi W., Yamane H., . . . Dairi T. (2008). Comparison of the enzymatic properties of ent-copalyl diphosphate synthases in the biosynthesis of phytoalexins and gibberellins in rice. Bioscience, Biotechnology, and Biochemistry , 72(2), 523-530.

Higuchi K., Kanazawa K., Nishizawa N.K., Chino M. \& Mori S. (1994). Purification and characterization of nicotianamine synthase from Fe-deficient barley roots. Plant and Soil , 165, 173-179.

Higuchi K., Watanabe S., Takahashi M., Kawasaki S., Nakanishi H., Nishizawa N.K. \& Mori S. (2001). Nicotianamine synthase gene expression differs in barley and rice under Fe-deficient conditions. The Plant Journal , 25(2), 159-167.

Holler S., Hajirezaei M.R., Von Wiren N. \& Frei M. (2014). Ascorbate metabolism in rice genotypes differing in zinc efficiency.Planta, 239(2), 367-379.

Hothorn T., Bretz F. \& Westfall P. (2008). Simultaneous inference in general parametric models. Biometrical Journal , 50(3), 346-363.

Huang S., Sasaki A., Yamaji N., Okada H., Mitani-Ueno N. \& Ma J.F. (2020). The ZIP transporter family member OsZIP9 contributes to root Zn uptake in rice under Zn-limited conditions. Plant Physiol ogy, 183, 1224-1234.

Inoue H., Higuchi K., Takahashi M., Nakanishi H., Mori S. \& Nishizawa N.K. (2003). Three rice nicotianamine synthase genes, OsNAS1, OsNAS2, and OsNAS3 are expressed in cells involved in long-distance transport of iron and differentially regulated by iron. The Plant Journal , 36(3), 366-381.

Ishimaru Y., Bashir K. \& Nishizawa N.K. (2011). Zn uptake and translocation in rice plants. Rice , 4, 21-27.

Ishimaru Y., Suzuki M., Kobayashi T., Takahashi M., Nakanishi H., Mori S. \& Nishizawa N.K. (2005). OsZIP4, a novel zinc-regulated zinc transporter in rice. Journal of Experimental Botany , 56(422), 32073214 . 
Jain R., Jenkins J., Shu S., Chern M., Martin J.A., Copetti D., . . . Ronald P.C. (2019). Genome sequence of the model rice variety KitaakeX.BMC genomics , 20, 905.

Kasote D.M., Katyare S.S., Hegde M.V. \& Bae H. (2015). Significance of antioxidant potential of plants and its relevance to therapeutic applications. International Journal of Biological Sciences, 11(8), 982-991.

Kato M. \& Shimizu S. (1987). Chlorophyll metabolism in higher plants. VII. Chlorophyll degradation in senescing tobacco leaves; phenolic-dependent peroxidative degradation. Canadian Journal of Botany, 65(4), 729-735.

Kawahara Y., de la Bastide M., Hamilton J.P., Kanamori H., McCombie W.R., Ouyang S., . . . Matsumoto T. (2013). Improvement of the Oryza sativa Nipponbare reference genome using next generation sequence and optical map data. Rice , 6, 4 .

Kim D., Langmead B. \& Salzberg S.L. (2015). HISAT: a fast spliced aligner with low memory requirements. Nature Methods , 12, 357-360.

Klein A.T., Yagnik G.B., Hohenstein J.D., Ji Z., Zi J., Reichert M.D., . . . Lee Y.J. (2015). Investigation of the chemical interface in the soybean aphid and rice-bacteria interactions using MALDI-mass spectrometry imaging. Analytical Chemistry, 87(10), 5294-5301.

Lee S., Jeong H.J., Kim S.A., Lee J., Guerinot M.L. \& An G. (2010a). OsZIP5 is a plasma membrane zinc transporter in rice. Plant Molecular Biology , 73(4-5), 507-517.

Lee S., Kim S.A., Lee J., Guerinot M.L. \& An G. (2010b). Zinc deficiency-inducible OsZIP8 encodes a plasma membrane-localized zinc transporter in rice. Molecules and Cells , 29(6), 551-558.

Lenth R. (2016). Least-squares means: the R package lsmeans. Journal of Statistical Software . doi: https://doi.org/10.18637/jss.v069.i01

Liao Y., Smyth G.K. \& Shi W. (2014). featureCounts: an efficient general purpose program for assigning sequence reads to genomic features. Bioinformatics , 30(7), 923-930.

Lilay G.H., Castro P.H., Campilho A. \& Assuncao A.G.L. (2019). The Arabidopsis bZIP19 and bZIP23 activity requires zinc deficiency - insight on regulation from complementation lines. Frontiers in Plant Science, 9, 1955.

Lilay G.H., Castro P.H., Guedes J.G., Almeida D.M., Campilho A., Azevedo H., . . . Assuncao A.G.L. (2020a). Rice F-bZIP transcription factors regulate the zinc deficiency response. Journal of Experimental Botany , 71(12), 3664-3677.

Lilay G. H., Persson D., Castro P.H., Liao F., Alexander R., Aarts M.G. \& Assuncao A.G.L. (2020b). The Arabidopsis bZIP19 and bZIP23 transcription factors act as zinc-sensors to control plant zinc status.bioRxiv . doi: https://doi.org/10.1101/2020.06.29.177287

Lin Y.F. \& Aarts M.G. (2012). The molecular mechanism of zinc and cadmium stress response in plants. Cellular and Molecular Life Sciences ,69(19), 3187-3206.

Lin Y.F., Liang H.M., Yang S.Y., Boch A., Clemens S., Chen C.C., . . . Yeh K.C. (2009). Arabidopsis IRT3 is a zinc-regulated and plasma membrane localized zinc/iron transporter. The New Phytologist, 182(2), 392-404.

Livak K.J. \& Schmittgen T.D. (2001). Analysis of relative gene expression data using real-time quantitative PCR and the 2- $\Delta \Delta \mathrm{CT}$ method. Methods , 25(4), 402-408.

López-Millán A.F., Ellis D.R. \& Grusak M.A. (2005). Effect of zinc and manganese supply on the activities of superoxide dismutase and carbonic anhydrase in Medicago truncatula wild type and raz mutant plants. Plant Science, 168(4), 1015-1022. 
Love M.I., Huber W. \& Anders S. (2014). Moderated estimation of fold change and dispersion for RNA-seq data with DESeq2. Genome Biology, 15, 550.

Lu X., Zhang J., Brown B., Li R., Rodríguez-Romero J., Berasategui A., . . Peters R.J. (2018). Inferring roles in defense from metabolic allocation of rice diterpenoids. The Plant Cell , 30, 1119-1131.

Marschner H. (2011). Marschner's mineral nutrition of higher plants. London: Academic Press.

Mathur D. (2014). Selection of suitable housekeeping genes for expression analysis in glioblastoma using quantitative RT-PCR.Annals of Neurosci ences, 21(2), 62-63.

McCall K.A., Huang C. \& Fierke C.A. (2000). Function and mechanism of zinc metalloenzymes. The Journal of Nutrition, 130(5S Suppl), 1437S-1446S.

Miller A.F. (2012). Superoxide dismutases: ancient enzymes and new insights. FEBS Letters , 586(5), 585595 .

Mittler R. (2017). ROS are good. Trends in Plant Science, 22(1), 11-19.

Mizuno D., Higuchi K., Sakamoto T., Nakanishi H., Mori S. \& Nishizawa N.K. (2003). Three nicotianamine synthase genes isolated from maize are differentially regulated by iron nutritional status. Plant physiology , 132(4), 1989-1997.

Nag P., Nag P., Paul A.K. \& Mukherji S. (1984). Toxic action of zinc on growth and enzyme activities of rice Oryza sativa L. seedlings.Environmental Pollution Series A, Ecological and Biological , 36(1), 45-59.

Nakano Y. \& Asada K. (1981). Hydrogen peroxide is scavenged by ascorbate-specific peroxidase in spinach chloroplasts. Plant and Cell Physiology, 22(5), 867-880.

Nanda A.K., Pujol V. \& Wissuwa M. (2017). Patterns of stress response and tolerance based on transcriptome profiling of rice crown tissue under zinc deficiency. Journal of Experimental Botany , 68(7), 1715-1729.

Nazri A.Z., Griffin J.H.C., Peaston K.A., Alexander-Webber D.G.A. \& Williams L.E. (2017). F-group bZIPs in barley-a role in Zn deficiency.Plant, Cell and Environment, 40(11), 2754-2770.

Palmgren M.G., Clemens S., Williams L.E., Krämer U., Borg S., Schjørring J.K. \& Sanders D. (2008). Zinc biofortification of cereals: problems and solutions. Trends in Plant Science , 13(9), 464-473.

Pilon M., Ravet K. \& Tapken W. (2011). The biogenesis and physiological function of chloroplast superoxide dismutases. Biochimica et Biophysica Acta, 1807(8), 989-998.

Ramesh S.A., Shin R., Eide D.J. \& Schachtman D.P. (2003). Differential metal selectivity and gene expression of two zinc transporters from rice. Plant Physiol ogy, 133, 126-134.

Reimers M. \& Carey V.J. (2006). Bioconductor: an open source framework for bioinformatics and computational biology. Methods in Enzymology, 411, 119-134.

Rodríguez-Celma J., Pan I.C., Li W., Lan P., Buckhout T.J. \& Schmidt W. (2013). The transcriptional response of Arabidopsis leaves to Fe deficiency. Frontiers in Plant Science 4, 276.

Sagardoy R., Morales F., López-Millán A.F., Abadía A. \& Abadía J. (2009). Effects of zinc toxicity on sugar beet (Beta vulgaris L.) plants grown in hydroponics. Plant Biology (Stuttgart, Germany), 11(3), 339-350.

Santos C.S., Ozgur R., Uzilday B., Turkan I., Roriz M., Rangel A.O.S.S., . . . Vasconcelos M.W. (2019). Understanding the role of the antioxidant system and the tetrapyrrole cycle in iron deficiency chlorosis.Plants (Basel, Switzerland) , 8(9), 348.

Saravanan M., Vasu K., Ghosh S. \& Nagaraja V. (2007). Dual role for Zn2+ in maintaining structural integrity and inducing DNA sequence specificity in a promiscuous endonuclease. The Journal of Biological Chemistry, 282(44), 32320-32326. 
Sekimoto H., Hoshi M., Nomura T. \& Yokota T. (1997). Zinc deficiency affects the levels of endogenous gibberellins in Zea mays L. Plant and Cell Physiology, 38(9), 1087-1090.

Shahid M., Pourrut B., Dumat C., Nadeem M., Aslam M. \& Pinelli, E. (2014). Heavy-metal-induced reactive oxygen species: phytotoxicity and physicochemical changes in plants. In Reviews of Environmental Contamination and Toxicology Volume 232 (ed D. M. Whitacre), pp. 1-44. Springer International Publishing, Cham.

Shanmugam V., Tsednee M. \& Yeh K.C. (2012). ZINC TOLERANCE INDUCED BY IRON 1 reveals the importance of glutathione in the cross-homeostasis between zinc and iron in Arabidopsis thaliana. The Plant Journal , 69(6), 1006-1017.

Shao J.F., Xia J., Yamaji N., Shen R.F. \& Ma J.F. (2018). Effective reduction of cadmium accumulation in rice grain by expressing OsHMA3 under the control of the OsHMA2 promoter. Journal of Experimental Botany , 69(10), 2743-2752.

Shimizu T., Jikumaru Y., Okada A., Okada K., Koga J., Umemura K., . . Yamane H. (2008). Effects of a bile acid elicitor, cholic acid, on the biosynthesis of diterpenoid phytoalexins in suspension-cultured rice cells. Phytochemistry , 69(4), 973-981.

Shinozaki D., Merkulova E.A., Naya L., Horie T., Kanno Y., Seo M., . . . Yoshimoto K. (2020). Autophagy increases zinc bioavailability to avoid light-mediated reactive oxygen species production under zinc deficiency.Plant physiology, 182, 1284-1296.

Silva M.L.D.S., Vitti G.C. \& Trevizam A.R. (2014). Heavy metal toxicity in rice and soybean plants cultivated in contaminated soil.Revista Ceres , 61(2), 248-254.

Stoyanova Z. \& Doncheva S. (2002). The effect of zinc supply and succinate treatment on plant growth and mineral uptake in pea plant.Brazilian Journal of Plant Physiology , 14(2), 111-116.

Suzuki M., Bashir K., Inoue H., Takahashi M., Nakanishi H. \& Nishizawa N.K. (2012). Accumulation of starch in Zn-deficient rice. Rice, 5, 9.

Suzuki M., Takahashi M., Tsukamoto T., Watanabe S., Matsuhashi S., Yazaki J., . . Nishizawa N.K. (2006). Biosynthesis and secretion of mugineic acid family phytosiderophores in zinc-deficient barley. ThePlant Journal , 48(1), 85-97.

Takaki H. \& Kushizaki M. (1977). Indole compounds in zinc-deficient plants. JARQ-Japan Agricultural Research Quarterly, 11(1), 18-23.

Tan L., Qu M., Zhu Y., Peng C., Wang J., Gao D., . . Chen C. (2020). ZINC TRANSPORTER5 and ZINC TRANSPORTER9 function synergistically in zinc/cadmium uptake. Plant Physiology, 183, 1235-1249.

Tan L., Zhu Y., Fan T., Peng C., Wang J., Sun L. \& Chen C. (2019). OsZIP7 functions in xylem loading in roots and inter-vascular transfer in nodes to deliver $\mathrm{Zn} / \mathrm{Cd}$ to grain in rice.Biochemical and Biophysical Research Communications , 512(1), 112-118.

Thimm O., Bläsing O., Gibon Y., Nagel A., Meyer S., Krüger P., . . Stitt M. (2004). MAPMAN: a user-driven tool to display genomics data sets onto diagrams of metabolic pathways and other biological processes. The Plant Journal , 37(6), 914-939.

Tian T., Liu Y., Yan H., You Q., Yi X., Du Z., . . Su Z. (2017). agriGO v2.0: a GO analysis toolkit for the agricultural community, 2017 update. Nucleic Acids Research , 45(W1), W122-W129.

Tiong J., Mcdonald G., Genc Y., Shirley N., Langridge P. \& Huang C.Y. (2015). Increased expression of six ZIP family genes by zinc (Zn) deficiency is associated with enhanced uptake and root-to-shoot translocation of Zn in barley (Hordeum vulgare). The New Phytologist, 207(4), 1097-1109. 
Tripathi D.K., Singh S., Gaur S., Singh S., Yadav V., Liu S., . . Sahi S. (2018). Acquisition and homeostasis of iron in higher plants and their probable role in abiotic stress tolerance. Frontiers in Environmental Science $, 5,86$.

Umemura K., Ogawa N., Shimura M., Koga J., Usami H. \& Kono T. (2003). Possible role of phytocassane, rice phytoalexin, in disease resistance of rice against the blast fungus Magnaporthe grisea. Bioscience, Biotechnology, and Biochemistry, 67(4), 899-902.

Verbruggen N., Hermans C. \& Schat H. (2009). Molecular mechanisms of metal hyperaccumulation in plants. The New Phytologist, 181(4), 759-776.

Vose P.B. (1982). Iron nutrition in plants: A world overview.Journal of Plant Nutrition , 5(4-7), 233-249.

Wang H. \& Jin J. (2007). Effects of zinc deficiency and drought on plant growth and metabolism of reactive oxygen species in maize (Zea mays L). Agricultural Sciences in China , 6(8), 988-995.

Warnes G., Bolker B., Bonebakker L., Gentleman R., Huber W., Liaw A., . . Venables B. (2005). gplots: Various $\mathrm{R}$ programming tools for plotting data. $R$ package version , 2, 1.

Westin G. \& Schaffner W. (1988). Heavy metal ions in transcription factors from HeLa cells: Sp1, but not octamer transcription factor requires zinc for DNA binding and for activator function. Nucleic Acids Research, 16(13), 5771-5781.

Wickham H. (2016). ggplot2: Elegant Graphics for Data Analysis. Switzerland: Springer.

Widodo B., Broadley M.R., Rose T., Frei M., Pariasca-Tanaka J., Yoshihashi T., . . . Wissuwa M. (2010). Response to zinc deficiency of two rice lines with contrasting tolerance is determined by root growth maintenance and organic acid exudation rates, and not by zinc-transporter activity. The New Phytologist , 186(2), 400-414.

Wintermans J.F.G.M. \& De Mots A. (1965). Spectrophotometric characteristics of chlorophylls a and b and their phenophytins in ethanol. Biochimica et Biophysica Acta , 109(2), 448-453.

Yang T.J.W., Lin W. \& Schmidt W. (2010). Transcriptional Profiling of the Arabidopsis iron deficiency response reveals conserved transition metal homeostasis networks. Plant Physiol ogy, 152, 2130-2141.

Yang X., Huang J., Jiang Y. \& Zhang H.S. (2009). Cloning and functional identification of two members of the ZIP (Zrt, Irt-like protein) gene family in rice (Oryza sativa L.). Molecular Biology Reports , 36(2), 281-287.

Yoshida S. (1976). Routine procedure for growing rice plants in culture solution. In Laboratory Manual for Physiological Studies of Rice. (eds S. Yoshida, D.A. Forno, J.H. Cook \& K.A. Gomez), pp. 61-66. International Rice Research Institute.

Yoshida S. \& Tanaka A. (1969). Zinc deficiency of the rice plant in calcareous soils. Soil Science and Plant Nutrition , 15(2), 75-80.

Zeng H., Zhang X., Ding M., Zhang X. \& Zhu Y. (2019a). Transcriptome profiles of soybean leaves and roots in response to zinc deficiency.Physiologia Plantarum , 167(3), 330-351.

Zeng H., Zhang X., Ding M. \& Zhu Y. (2019b). Integrated analyses of miRNAome and transcriptome reveal zinc deficiency responses in rice seedlings. BMC Plant Biology , 19, 585.

Zhang, X., Jiang, H., Wang, H., Cui, J., Wang, J., Hu, J., . . Xue D. (2017). Transcriptome analysis of rice seedling roots in response to potassium deficiency. Scientific Reports , 7(1), 5523.

Table 1 The number of differentially expressed genes (DEGs) in each comparison group: Zn deficiency (-Zn), normal Zn (NZn) and excess Zn (+Zn). R = root and $\mathrm{S}=$ shoot. 


\begin{tabular}{llll}
\hline Comparison & Total DEGs $^{+}$ & Upregulation & Downregulation \\
\hline$-Z n / N Z n \_R$ & 188 & 116 & 72 \\
$-Z n / N Z n \_S$ & 186 & 106 & 80 \\
+Zn/NZn_R & 820 & 182 & 638 \\
+Zn/NZn_S & 163 & 74 & 89 \\
$-Z n /+Z n \_R$ & 723 & 541 & 182 \\
$-Z n /+Z n \_S$ & 287 & 170 & 117 \\
\hline
\end{tabular}

+ A gene was considered as a DEG if $\mid \log _{2}$ fold change| between two sample groups was [?] 1 (adjusted p-value $<0.05)$.

\section{Figure Legends}

Figure 1 Rice physiology in response to Zn deficiency and excess at 3, 14 and 21 DAT. (A) Morphological comparison of shoots and roots of rice plants under -Zn, NZn and +Zn treatments at 3, 14 and 21 DAT (scale bar $=10 \mathrm{~cm}$ ). Bar charts show the quantitative measurements of root length $(\mathbf{B})$, root dry weight (C), plant height (D), shoot dry weight (E), total chlorophyll content (F), shoot Zn concentration $(\mathbf{G})$ and root $\mathrm{Zn}$ concentration $(\mathbf{H})$. Zn deficiency $(-\mathrm{Zn})$ is represented by white bars, normal $\mathrm{Zn}(\mathrm{NZn})$ by gray bars and excess $\mathrm{Zn}(+\mathrm{Zn})$ by black bars. Zn concentration is indicated as $\mathrm{mg}$ per $\mathrm{kg}$ plant dry weight (DW). Two-way ANOVA and Tukey's post hoc test were used for all measurements, with different letters denoting a significant difference $(\mathrm{p}<0.05)$.

Figure 2 An overview of RNA-Seq data comparing gene expression in rice seedlings in response to Zn deficiency and excess at 3 DAT. (A)The number of DEGs between $\mathrm{Zn}$ treatments is shown for roots and shoots.(B) GO enrichment analysis of DEGs in three groups: biological process (BP), cellular component (CC) and molecular function (MF). Enrichment significance is shown by the length of each bar, and gene numbers for each enriched GO term are indicated by the color intensity of the bars. A gene was considered to be differentially expressed if $\mid \log _{2}$ fold change $\mid$ between $-Z n$ and $+Z n$ samples was [?] 1 (adjusted p-value $<0.05$ ). $-\mathrm{Zn}=\mathrm{Zn}$ deficient treatment and $+\mathrm{Zn}=$ excess $\mathrm{Zn}$ treatment.

Figure 3 Effects of $\mathrm{Zn}$ deficiency and excess on the expression of F-OsbZIP transcription

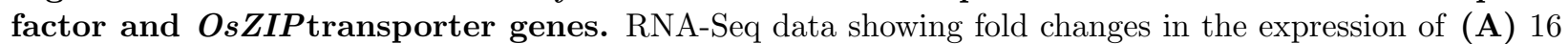
OsZIP genes, and (B) OsbZIP $48, O s b Z I P 49$ and OsbZIP50 in the $-\mathrm{Zn} / \mathrm{NZn}$ and $+\mathrm{Zn} / \mathrm{NZn}$ comparisons for roots and shoots at 3 DAT. RT-qPCR data showing fold changes in the expression of (C) OsZIP4, OsZIP5 ,OsZIP 7 and OsZIP8 , and (D) OsbZIP48,OsbZIP49 and OsbZIP50 genes at 3, 14 and 21 DAT. Upregulated genes are shown in red and downregulated genes in blue. In the sample comparison, $\mathrm{R}=$ root and $\mathrm{S}=$ shoot. For the RT-qPCR results, values for Livak fold difference are the mean (error bars indicate $\mathrm{SD}$ ) of four biological replicates with OsUbi1 as the housekeeping reference gene. Zn deficiency (-Zn) is represented by white bars, normal Zn $(\mathrm{NZn})$ by gray bars and excess $\mathrm{Zn}(+\mathrm{Zn})$ by black bars. bZIP= gene encoding basic leucine zipper transcription factor, $Z I P=$ gene encoding zinc-regulated transporter, iron-regulated transporter-like protein. Three-way ANOVA and Tukey's post hoc test were used for all measurements, with different letters denoting a significant difference $(\mathrm{p}<0.05)$.

Figure 4 Effects of $\mathrm{Zn}$ deficiency and excess on the expression of nutrient transport-related genes and shoot nutrient concentrations.(A) RNA-Seq data showing fold changes in the expression of 17 GO-enriched ion transport genes in the $-\mathrm{Zn} / \mathrm{NZn}$ and $+\mathrm{Zn} / \mathrm{NZn}$ comparisons for roots and shoots at 3 DAT. (B) MapMan transport annotation results showing the expression change patterns of nutrient transport-related DEGs (-Zn/+Zn comparison) in the roots at 3 DAT.(C) RT-qPCR data showing fold changes in the expression of the mugineic acid phytosiderophore biosynthesis-related genes OsNAS3and OsNAAT1 in the roots and shoots of rice plants under -Zn, NZn and +Zn conditions at 3, 14 and 21 
DAT. (D) Shoot nutrient concentrations of rice plants under -Zn, NZn and +Zn conditions at 3,14 and 21 DAT. Upregulated genes are shown in red and downregulated genes in blue. In the sample comparison, $\mathrm{R}=$ root and $\mathrm{S}=$ shoot. For RT-qPCR results, values for Livak fold difference are the mean (error bars indicate SD) of four biological replicates with OsUbi1 as the housekeeping reference gene. Zn deficiency $(-\mathrm{Zn})$ is represented by white bars, normal $\mathrm{Zn}(\mathrm{NZn})$ by gray bars and excess $\mathrm{Zn}(+\mathrm{Zn})$ by black bars. NAS $=$ nicotianamine synthase gene and $N A A T=$ nicotianamine aminotransferase gene. Two-way ANOVA (for elemental analysis)/Three-way ANOVA (for RT-qPCR) and Tukey's post hoc test were used for all measurements, with different letters denoting a significant difference $(\mathrm{p}<0.05)$.

Figure 5 Effects of $\mathrm{Zn}$ deficiency and excess on the expression of peroxidase genes, ROS formation and activities of $\mathrm{H}_{2} \mathrm{O}_{2}$-scavenging enzymes. (A)RNA-Seq data showing fold changes in the expression of 44 genes encoding GO-enriched iron-binding proteins in the $-\mathrm{Zn} / \mathrm{NZn}$ and $+\mathrm{Zn} / \mathrm{NZn}$ comparisons for roots and shoots at 3 DAT. DAB (B) and NBT (C)staining show the accumulation of $\mathrm{H}_{2} \mathrm{O}_{2}$ and $\mathrm{O}_{2}{ }^{-}$respectively in leaves of rice plants under $-\mathrm{Zn}, \mathrm{NZn}$ and $+\mathrm{Zn}$ conditions at 14 DAT (scale bar $=5 \mathrm{~mm}$ ).(D) Enzymatic activities (units per $\mathrm{mg}$ protein) of APX, CAT and GR in shoots of rice plants under -Zn, NZn and + Zn conditions at 3, 14 and 21 DAT. Upregulated genes are shown in red and downregulated genes in blue. In the sample comparison, $\mathrm{R}=$ root and $\mathrm{S}=$ shoot. For enzymatic activity, $\mathrm{Zn}$ deficiency $(-\mathrm{Zn})$ is represented by white bars, normal $\mathrm{Zn}(\mathrm{NZn})$ by gray bars and excess $\mathrm{Zn}(+\mathrm{Zn})$ by black bars. $\mathrm{APX}=$ ascorbate peroxidase, $\mathrm{CAT}=$ catalase, $\mathrm{GR}=$ glutathione reductase. Two-way ANOVA and Tukey's post hoc test were used for all measurements, with different letters denoting a significant difference $(\mathrm{p}<0.05)$.

Figure 6 Effects of $\mathrm{Zn}$ deficiency and excess on the expression of genes encoding enzymes that synthesize defense-related diterpenoid compounds. (A) RNA-Seq data showing fold changes in the expression of 12 genes encoding GO-enriched magnesium-binding proteins in the $-\mathrm{Zn} / \mathrm{NZn}$ and $+\mathrm{Zn} / \mathrm{NZn}$ comparisons for roots and shoots at 3 DAT. Upregulated genes are shown in red and downregulated genes in blue. In the sample comparison, $\mathrm{R}=$ root and $\mathrm{S}=$ shoot. (B) The expression of five genes encoding enzymes that synthesize defense-related diterpenoid compounds may be enhanced by excess Zn. DEGs enhanced (OsCPS2/4 and OsKSL4/7/8) or repressed (OsKSL5 ) by excess Zn are shown as red/pink or blue boxes, respectively, whereas constitutive genes (OsCPS1 and OsKSL1/2/10) are shown as gray boxes. Stronger expression is represented by deeper color. GGPP $=$ geranylgeranyl diphosphate, CPP $=$ copalyl diphosphate, $\mathrm{GA}=$ gibberellin, $C P S=$ copalyl diphosphate synthase gene, $K S=$ kaurene synthase gene, $K S L=$ kaurene synthase-like gene.

Figure $7 \mathrm{Model}$ of rice response to $\mathrm{Zn}$ stress. When rice is starved of $\mathrm{Zn}$, a range of divalent cations are translocated to the shoots due to the increased expression of promiscuous Zn transporters and chelators. The accumulation of these cations during prolonged Zn deficiency is harmful to rice plants, which have therefore evolved mechanisms to prevent cation accumulation and mediate important $\mathrm{Zn}$ deficiency responses. This is achieved by the functional clustering of enzymes with the same metal cofactor. For example, rice plants detect a slight increase in shoot $\mathrm{Fe}$ and $\mathrm{Ca}$ levels at the onset of $\mathrm{Zn}$ deficiency and induce genes encoding $\mathrm{Fe} / \mathrm{Ca}$ binding peroxidases (3 DAT). This increases the abundance and activity of ascorbate peroxidase (APX) in leaves at 14 and 21 DAT. APX requires Fe as a cofactor, so the greater abundance of APX sequesters free Fe (thus helping to prevent chlorosis, which in Zn-deficient leaves is triggered by excess $\mathrm{H}_{2} \mathrm{O}_{2}$ being converted into $\mathrm{OH}^{*}$ via the Fe-dependent Fenton reaction). The increase in APX activity also scavenges more $\mathrm{H}_{2} \mathrm{O}_{2}$ thus reducing the likelihood of chlorosis via two mechanisms. In response to excess $\mathrm{Zn}$, genes encoding $\mathrm{Mg}$ binding proteins are induced in rice shoots at $3 \mathrm{DAT}$, presumably due to the detection of falling intracellular $\mathrm{Mg}$ levels. These Mg-binding proteins include enzymes in the diterpenoid biosynthesis pathway, potentially leading to the accumulation of diterpenoid secondary metabolites such as oryzalexin S, momilactones A and $\mathrm{B}$, and phytocassanes A-E, which kill fungal and bacterial pathogens. Mehler reaction is depicted by purple arrows and Fenton reaction by light blue arrows. $-\mathrm{Zn}=\mathrm{Zn}$ deficiency, NZN $=$ normal Zn, $+\mathrm{Zn}=$ excess Zn, GGPP $=$ geranylgeranyl diphosphate, $\mathrm{CPP}=$ copalyl diphosphate, $C P S=$ copalyl diphosphate synthase gene, $K S L=$ kaurene synthase-like gene. 


\section{Supplementary Figure Legends}

Figure S1 Rice physiology in response to Zn deficiency and excess at 3, 14 and 21 DAT. (A) Morphological comparison,(B) root fresh weight, (C) shoot fresh weight, and(D) SPAD (relative chlorophyll content) of rice plants under $-\mathrm{Zn}, \mathrm{NZn}$ and $+\mathrm{Zn}$ conditions at 3, 14 and 21 DAT (scale bar=10cm).(E) Chlorophyll $a$ and $(\mathbf{F})$ chlorophyll $b$ content of rice plants at 14 and 21 DAT. Two-way ANOVA and Tukey's post hoc test were used for all measurements, with different letters denoting a significant difference $(\mathrm{P}<$ $0.05)$. Zn deficiency $(-\mathrm{Zn})$ is represented by white bars, normal $\mathrm{Zn}(\mathrm{NZn})$ by gray bars and excess $\mathrm{Zn}(+\mathrm{Zn})$ by black bars.

Figure S2 Principal component analysis scatter plot showing the relatively small variation between three biological replicates and relatively large variation between samples of different tissues and $\mathrm{Zn}$ treatments. $-\mathrm{Zn}=\mathrm{Zn}$ deficiency, $\mathrm{NZn}=$ normal $\mathrm{Zn}$ control, $+\mathrm{Zn}=$ excess $\mathrm{Zn}, \mathrm{R}=$ root and $S=$ shoot. The numbers represent different biological replicates.

Figure S3 Root nutrient concentrations in rice plants under $-\mathrm{Zn}, \mathrm{NZn}$ and $+\mathrm{Zn}$ conditions at 3, 14 and 21 DAT. Bar charts show concentration of the micronutrients (A) Mn, (B) Fe, and (C) Cu, as well as the macronutrients (D) P,(E) Na, (F) Ca, (G) K and (H) Mg. Two-way ANOVA and Tukey's post hoc test were used for all measurements, with different letters denoting a significant difference $(\mathrm{P}<0.05)$. $\mathrm{Zn}$ deficiency $(-\mathrm{Zn})$ is represented by white bars, normal $\mathrm{Zn}(\mathrm{NZn})$ by gray bars and excess $\mathrm{Zn}(+\mathrm{Zn})$ by black bars.

Figure S4 Translocation rate of nutrients in rice plants under $-\mathrm{Zn}, \mathrm{NZn}$ and $+\mathrm{Zn}$ conditions at 3 , 14 and 21 DAT. Bar charts show translocation rates of the micronutrients (A) Mn,(B) Fe, (C) $\mathrm{Cu}$, as well as the macronutrients(D) P, (E) Na, (F) Ca, (G) K and(H) Mg based on the shoot concentration divided by the root concentration. Two-way ANOVA and Tukey's post hoc test were used for all measurements, with different letters denoting a significant difference $(\mathrm{P}<0.05)$. Zn deficiency $(-\mathrm{Zn})$ is represented by white bars, normal Zn $(\mathrm{NZn})$ by gray bars and excess Zn $(+\mathrm{Zn})$ by black bars.

Figure S5 RNA-Seq data showing fold change in the expression of 22 genes encoding GOenriched calcium-binding proteins in the $-\mathrm{Zn} / \mathrm{NZn}$ and $+\mathrm{Zn} / \mathrm{NZn}$ comparisons for roots and shoots at 3DAT. Upregulated genes are shown in red and downregulated genes in blue. $-\mathrm{Zn}=\mathrm{Zn}$ deficiency, $\mathrm{NZn}=$ normal $\mathrm{Zn},+\mathrm{Zn}=$ excess $\mathrm{Zn}, \mathrm{R}=$ root and $\mathrm{S}=$ shoot.

Figure S6 Effects of $\mathrm{Zn}$ deficiency and excess on leaf ROS formation at 3 and 21 DAT. DAB staining showing the effects of $\mathrm{H}_{2} \mathrm{O}_{2}$ accumulation in the leaves of rice plants under $-\mathrm{Zn}, \mathrm{NZn}$ and $+\mathrm{Zn}$ conditions (A) at 3 DAT and (C) 21 DAT. NBT staining showing the effects of $\mathrm{O}_{2}$-accumulation in the leaves of rice plants under with $-\mathrm{Zn}, \mathrm{NZn}$ and $+\mathrm{Zn}$ conditions (B) at 3 DAT and (D) 21 DAT (scale bar = $5 \mathrm{~mm}) .-\mathrm{Zn}=\mathrm{Zn}$ deficiency, $\mathrm{NZn}=$ normal $\mathrm{Zn},+\mathrm{Zn}=$ excess $\mathrm{Zn}$.

\section{Supplementary Table Captions}

Table S1 Primers used for RT-qPCR amplifications.

Table S2 Statistics of total, total mapped and uniquely mapped reads per RNA-Seq sample.

Table S3 Gene list and expression details of enriched GO terms.

Table S4 MapMan transport annotation results showing the expression change patterns of nutrient transport-related DEGs identified between $-\mathrm{Zn}$ - and +Zn-treated plants in roots at 3DAT. 

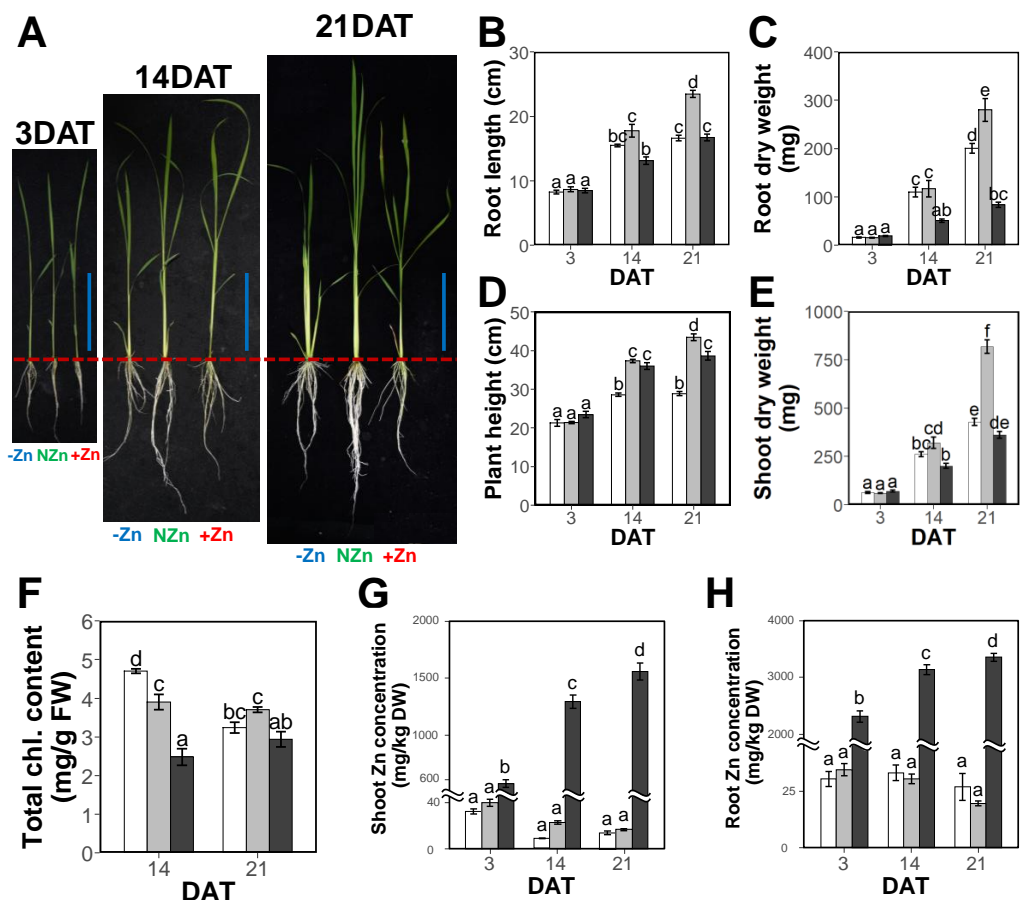

H

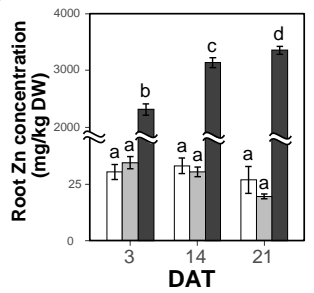

A

B

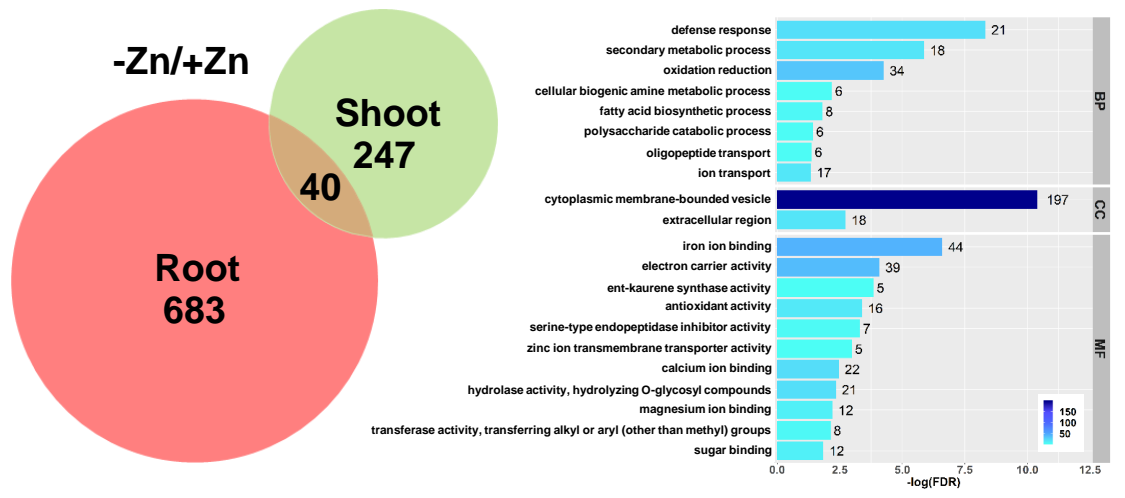


A

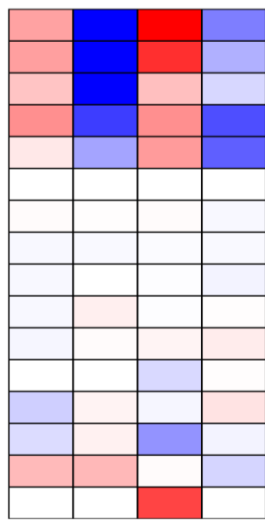

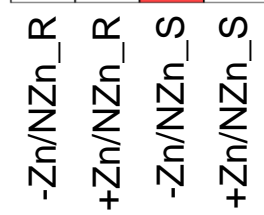

C OszIP4

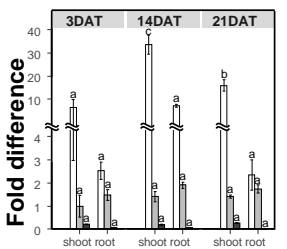

Os05g0472400: OsZIP9 Os08g0207500: OsZIP4 Os05g0472700: OsZIP5 Os07g0232800: OsZIP8 Os05g0198400: OsZIP7 Os03g0667300: OsIRT2 Os08g0100200: OsZIP16 Os02g0196000: OsZIP13 Os05g0164800: OsZIPG Os05g0316100: OsZIP11 Os08g0467400: OsZIP14 Os03g0667500: OsIRT1 Os03g0411800: OsZIP2 Os01g0972200: OsZIP1 Os04g0613000: OsZIP3 Os06g0566300: OsZIP10

B
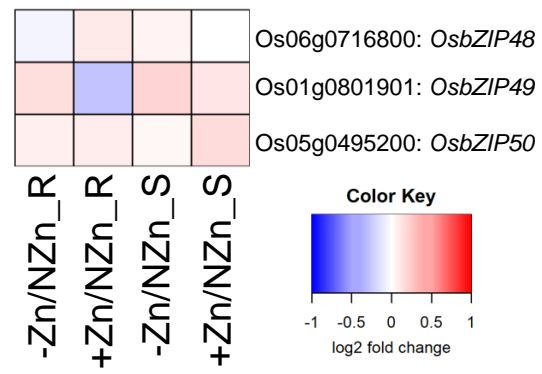

D

OsbZIP48

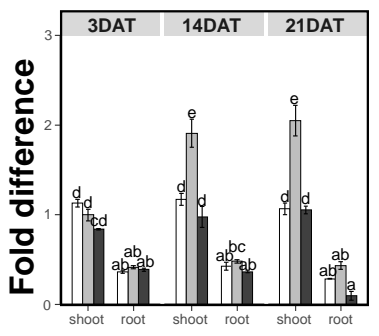

Color Key

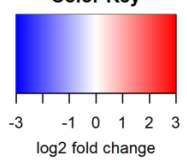

OsZIP5

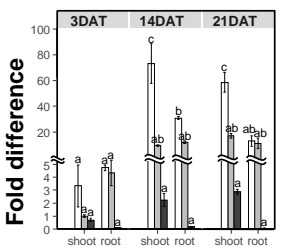

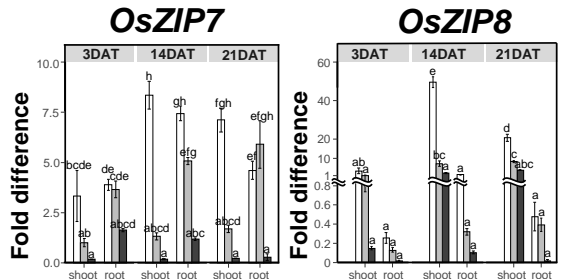

OsbZIP49

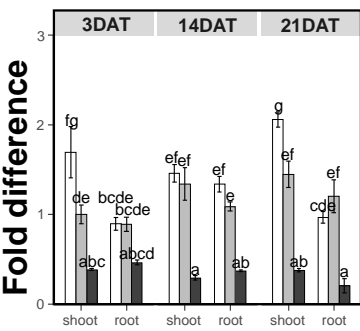

OsbZIP50

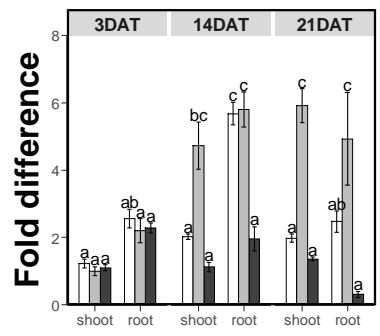


A

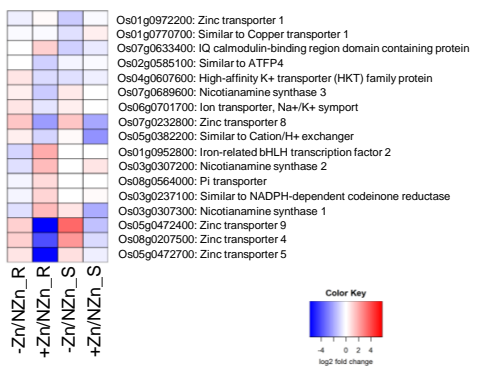

C OSNAS3

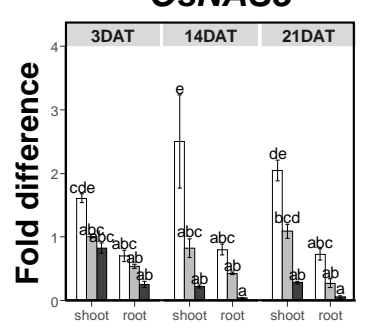

B

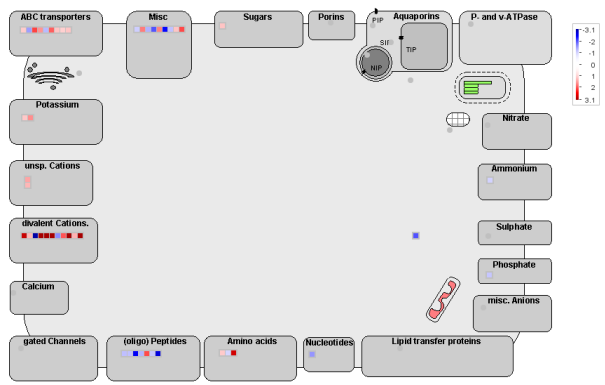

OsNAAT1

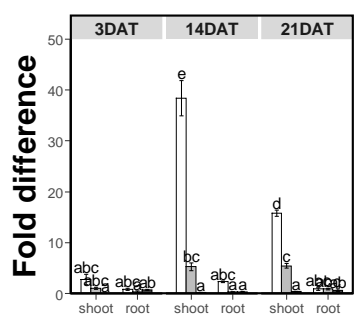

D
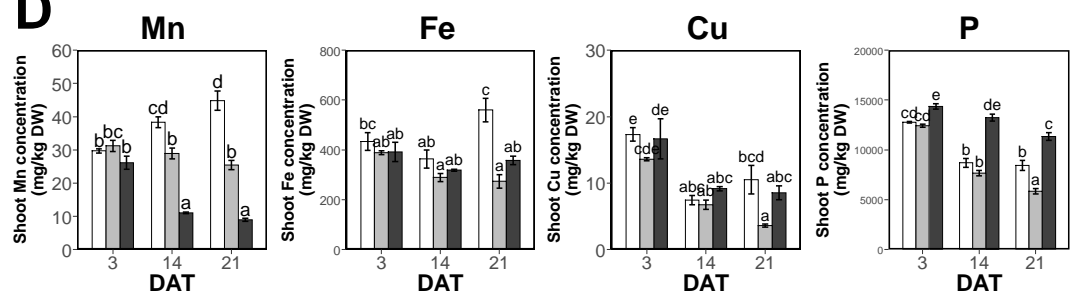

$\mathrm{Na}$
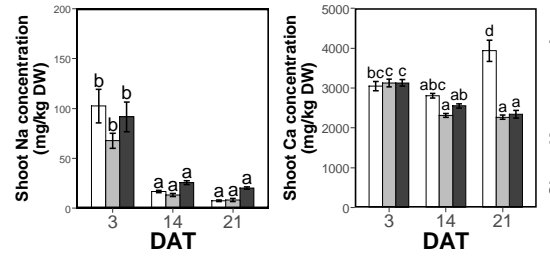

Mg

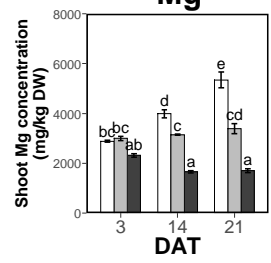


A
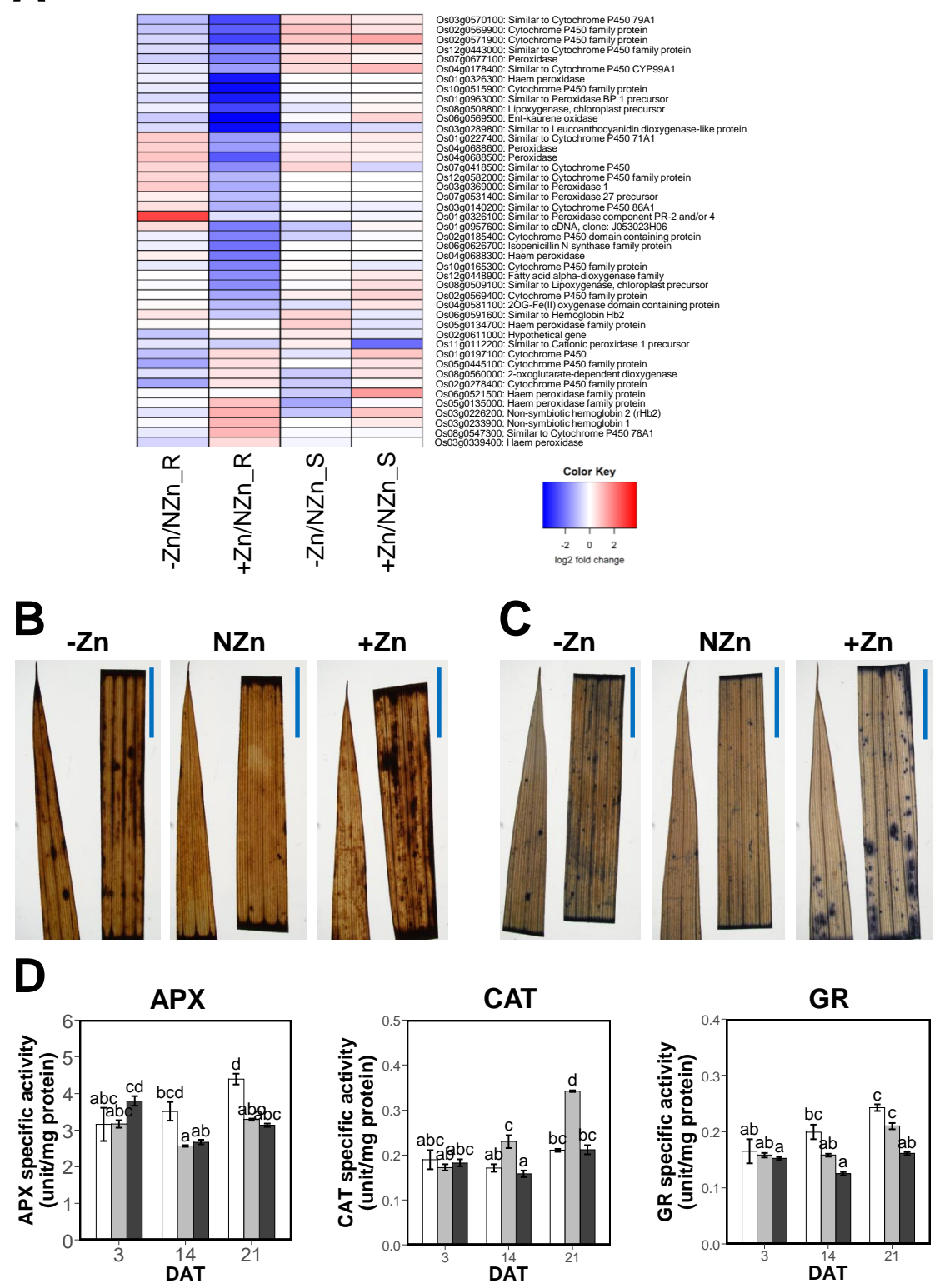
A

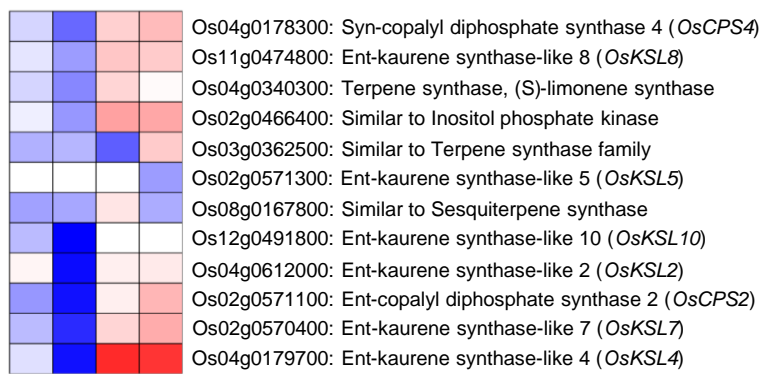

$\llbracket \llbracket \omega の$

ᄃ ज्ञ

之姿这

$\underset{N}{N} \underset{+}{N} \underset{+}{N}$

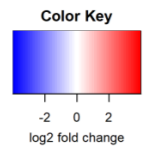

B

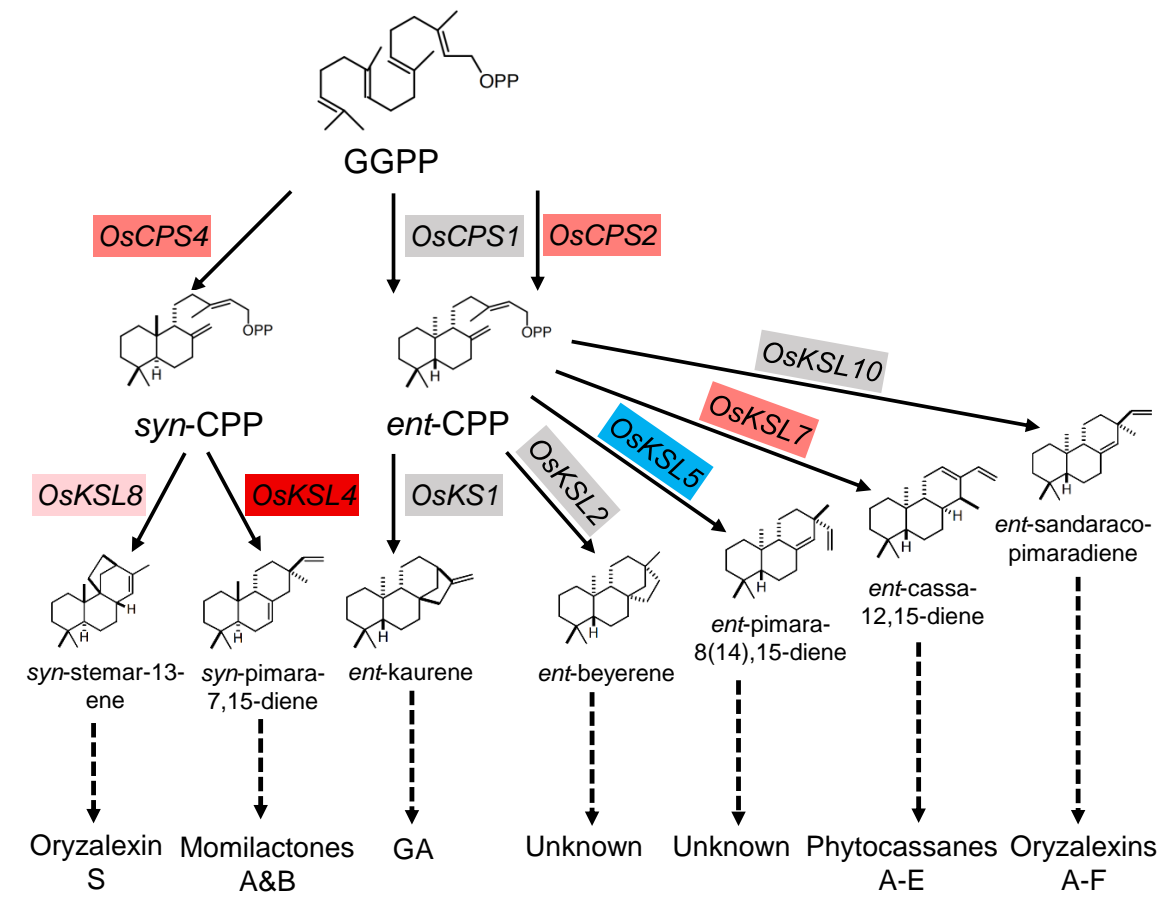




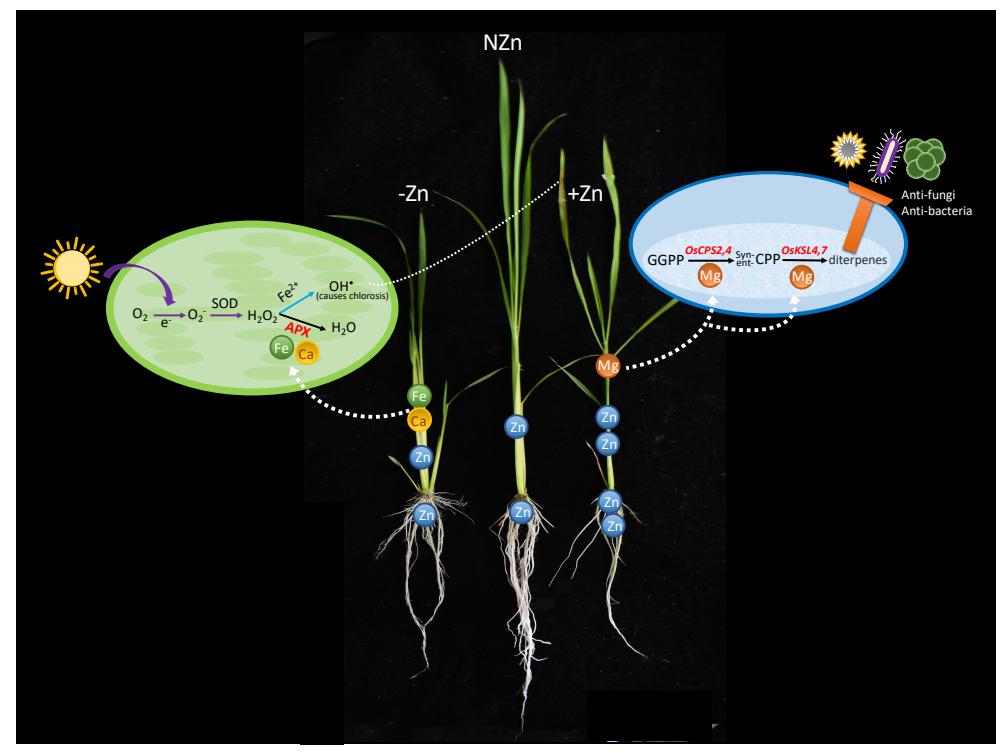

